\title{
Influence of Metallic Powder Characteristics On Extruded Feedstock Performance For Indirect Additive Manufacturing
}

Cyril Santos ( $\square$ cyril.santos@ipleiria.pt)

IPL: Instituto Politecnico de Leiria https://orcid.org/0000-0001-8155-5005

Daniel Gatões

University of Coimbra

Fábio Cerejo

Instituto Pedro Nunes

Teresa Vieira

University of Coimbra

\section{Research Article}

Keywords: Additive Manufacturing, Copper, MEX, Filament, micro-CT

Posted Date: June 2nd, 2021

DOI: https://doi.org/10.21203/rs.3.rs-536396/v1

License: (a) (i) This work is licensed under a Creative Commons Attribution 4.0 International License.

Read Full License

Version of Record: A version of this preprint was published at Materials on November 24th, 2021. See the published version at https://doi.org/10.3390/ma14237136. 


\section{Abstract}

Material Extrusion (MEX) of metallic powder-based filaments has been showing great potential as an additive manufacturing technology. MEX provides an easy solution, as an alternative to direct additive manufacturing technologies (e.g. SLM, EBM, DED) for problematic metallic powder, like copper powder, due to its reflectivity and thermal conductivity. MEX, an indirect technology, consists of 5 steps optimising metal powder, mixing (feedstock), filament production, shaping, debinding and sintering. The great challenge in MEX is, undoubtedly, filament manufacturing for optimal green density, and consequently the sintered properties. The filament, to be extrudable, must accomplish at optimal powder volume concentration (CPVC) with good rheological performance, flexibility, and stiffness. These have a main role in the quality of the 3D objects after debinding and sintering. In this study, a feedstock composition (similar binder, additives and CPVC - 61\% vol.) of copper with three different particle powder characteristics was selected, in order to highlight their role. The quality of the filaments, strands and 3D objects was analyzed by micro-CT highlighting the influence of the different powder characteristics on the homogeneity and defects of the greens. Sintered filaments were also analysed, regarding hardness, microstructure and a comparison between green and sintered defects, using micro-CT. The filament based on particles powder with $D_{50}$ close to $11 \mu \mathrm{m}$ and straight distribution of particles size shows the best homogeneity and lower defects.

\section{Introduction}

Additive Manufacturing (AM) has gathered a great amount of interest in the past two decennia for various fields of applications [1]. After the boom of direct processes (i.e. Selective Laser Melting (SLM), Electron Beam Manufacturing (EBM), Direct Energy Deposition (DED)), two indirect technologies assume more and more the future (Binder Jetting (BJ) and Material Extrusion (MEX)), due to their simplicity, reliability, low cost and a wide range of different printing materials available. The last one is well known, particularly for polymeric materials, with the name Fused Deposition Modeling (FDM). When applied to the mixing of metallic/ceramic powder particles and organic binder and/or additives based on polymers adopted the standard name of Material Extrusion [2-6]. This process for 3D object shaping is based on FDM but the filament manufacturing is similar to Powder Metal Extrusion Process (PEP) and Powder Injection Molding (PIM). Both these processes use as feedstock polymers and organic materials with the highest feasible metal powder content, designated by Critical Powder Volume Concentration (CPVC) [7]. A feedstock that consists of a powder with optimal characteristics and appropriate binder are determinant factors to achieve quality in the final 3D object $[8,9]$.

Like in Powder Extrusion Process/Injection Molding (PEP/PIM), the parts produced by MEX use filaments with a high volume percentage of metals particles, typically between $50-65$ vol.-\% [10-12], and need two subsequent steps: debinding, to promote binder removal, and sintering to attain a dense 3D object (Fig. 1). Nevertheless, PIM Feedstocks result in a brittle filament form, thus it is necessary to optimize the mixture to achieve filament requirements for MEX, such as a good balance between suitable rheology properties, stiffness and flexibility. 
Nowadays, commercial filaments with metal particles are emerging, although most of them have a low content of metal powder or use PLA or ABS as the binder, which means that the main goals are the aesthetic appearance of the products or to increase properties of the master polymer $[13,14]$.

For stainless steel, different studies reveal that powder must have (3Ss): particle size $D_{50}$ from $5 \mu \mathrm{m}$ to 15 $\mu \mathrm{m}$; a particle size distribution monomodal; and a shape factor close to 1 [12], similar to the ones used in PIM.

Copper, particularly pure copper, is a widely applied metal in engineering applications due to the combination of suitable mechanical strength and excellent thermal and electrical properties. However, the processing of copper by AM has still a lot of research work and developments to be done to match the industry requirements and repeatability of the process. A few studies were made with copper using Selective Laser Melting (SLM) [2]. Although SLM has demonstrated to successfully work with a comprehensive range of metals, it has disadvantages when it comes to the fabrication of copper due to the high reflectivity of this metal to the laser beam, particularly for near-infrared radiation, and high thermal conductivity that leads to rapid heat dissipation and an uncontrolled molten pool [15], thus resulting in parts with significant porosity (11.9-17.0\%) [16-18]. In order to achieve dense copper parts, a higher laser energy density is required which means a higher power laser source and, therefore, an increase in energy consumption. Some studies regarding SLM of pure copper using a greater output laser power reported theoretical density values between 96.6 and $99.4 \%$ in self-developed platforms [19-21].

These are the reasons for the selection of copper powder as a material to highlight the role of the MEX as an effective processing technology.

In summary, the production of 3D objects made of copper powder by direct additive manufacturing, particularly those associated with the liquid state (SLM), entails several problems overcome with the indirect MEX process. Besides a significant research work about powder characteristics role, they focus essentially on steel powder. However, the properties of steel and copper powder oblige to analyse in detail these powder particles. And, according to the available literature, no scientific studies have investigated the influence of the application of MEX technology for the production of densified copper parts, in spite of the company Markforged having commercialized copper filaments for MEX, recently [22].

Therefore, it is crucial to research in order to have a complete understanding of powder characteristics, particularly of the three main steps involved in the filament process, namely: mixing the constituents of the filaments (copper powder, binder and additives), extrusion (filament manufacturing) and individual strand extrusion for 3D shaping.

\section{Characterization Techniques And Material}

3.1. Experimental conditions 
The powder particle size and the particle size distribution were measured by laser diffraction spectrometry (LDS) on a Malvern Instruments Mastersizer 3000 (Malvern Instruments Ltd, Worcestershire, UK), following ISO 13320:2009. The analysis of particles powder, filament and strands morphology was made by scanning electron microscopy (SEM) on a Tescan Vega 3 (Tescan, Brno, Czech Republic), and a FEI Quanta 400FEG (FEI Europe BV, Eindhoven, Netherlands). The structure phase characterization of the powder and greens were evaluated by X-ray diffraction (XRD) on a Philips X'Pert diffractometer (Philips, Eindhoven, Netherlands), according to EN 13925:2003, the current intensity was $35 \mathrm{~mA}$ and voltage of $40 \mathrm{kV}$. The wavelength radiation was cobalt $(\mathrm{Ka} 1=0.17810 \mathrm{~nm}$ and $\mathrm{Ka} 2=0.17928 \mathrm{~nm})$. The acquisition conditions used a Bragg-Brentano $(\theta-2 \theta)$ geometry and a step of $0.04^{\circ} / \mathrm{s}$. The thermogravimetric analyses (TGA ) were performed on a PerkinElmer STA 6000 (Waltham, MA, USA).

The filaments were analysed by a non-destructive method using X-ray micro computed tomography (micro-CT), Bruker SkyScan 1275 (Bruker, Kontich, Belgium). An acceleration voltage of $80 \mathrm{kV}$ and a beam current of $125 \mu \mathrm{A}$ was set while using a $1 \mathrm{~mm}$ copper filter and step-and-shoot mode. Pixel size was set to the equipment minimum of $5.67 \mu \mathrm{m}$ and random mode was used. 1056 projection images were acquired at $0.2^{\circ}$ angular step with 3 frames average per step using an exposure time of $65 \mathrm{~ms}$. In what concerns strands, they were scanned with an acceleration voltage of $50 \mathrm{kV}$ and a beam current of $80 \mu \mathrm{A}$, using as a filter aluminium with $1 \mathrm{~mm}$ thickness, and an exposure time of $230 \mathrm{~ms}$. The 3D objects and sintered filaments were scanned using an acceleration voltage of $100 \mathrm{kV}$ and a beam current of $100 \mu \mathrm{A}$ using a 1 $\mathrm{mm}$ copper filter. 3D Objects projection images (529) were acquired at $0.4^{\circ}$ angular step with 8 frames average per step using an exposure time of $245 \mathrm{~ms}$, sintered filaments projection images (1056) were acquired at $0.2^{\circ}$ angular step with 3 frames average per step and a $225 \mathrm{~ms}$ exposure time. All omitted conditions on the strands and parts were similar to the ones used on the filament. The micro-CT images were reconstructed with dedicated manufacturer software.

Hardness measurements were performed with a microhardness tester Shimadzu HMV (Shimadzu Corporation, Kyoto, Japan). For each measurement, a load of $98 \mathrm{mN}$ was applied for 15 seconds by a Vickers indenter.

\subsection{Copper powder characterization}

Three copper powder with essentially two different characteristics: particle size and particle size distribution, were tested. A similar organic mixing based on polymeric materials (master binder, backbone and plasticizer) with identical thermal cycle heat treatments for debinding and sintering were mixed (Table 1) [23]. Besides the selected binder (a mixture of polyolefin waxes and ethylenic polymers) [24], the additives chosen are necessary to attain a feasible stiffness (backbone) and flexibility (plasticizer) in a filament, that means a thermoplastic elastomer (TPE) and a plasticizer, respectively. The green filaments developed based on this procedure were constituted by copper powder (purity 99,99\%), with different particle size and particle size distribution.

Table 1- Composition of organic mixing 


\begin{tabular}{|llll|}
\hline & Master binder & Additives & \\
\cline { 3 - 4 } & & Backbone & Plasticizer \\
\hline Vol (\%) & 77.5 & 17.5 & 5.0 \\
\hline Density $\left(\mathrm{kg} / \mathrm{m}^{3}\right)$ & 970 & 1025 & 965 \\
\hline
\end{tabular}

The three different copper powder particle highlight the role of particle size and particle size distribution of particles in the quality of filament, strand and consequently in the final product and were furnished by Ecka (type A) and Alfa Aesar (type B, C) (Table 2).

The powder particles sizes are: (A) with $D_{50}$ equal $28.00 \mu \mathrm{m}$, (B) $11.30 \mu \mathrm{m}$ and (C) $3.97 \mu \mathrm{m}$, and particle size distribution from a bimodal with wide distribution $(A)$ up to monomodal with a very narrow distribution (C) (Fig. 2).

Table 2 shows the different particle size distribution of the three different copper powder, used in the present study.

Table 2

Characteristics of the different types of copper.

\begin{tabular}{|lllll|}
\hline Powder & $D_{10}[\mu \mathrm{m}]$ & $D_{50}[\mu \mathrm{m}]$ & $D_{90}[\mu \mathrm{m}]$ & $\rho[\mathrm{Kg} / \mathrm{m3}]$ \\
\hline A & 8.57 & 28.00 & 46.60 & 8896 \\
\hline B & 7.75 & 11.30 & 16.20 & 8648 \\
\hline C & 1.95 & 3.97 & 6.67 & 8427 \\
\hline
\end{tabular}

Whatever the selected copper powder, the shape factor was always close to 1 (Fig. 3).

XRD of the highest diameter powder shows pure copper (ICDD 075-1531) and the presence of copper oxide phase (ICDD 04-0836) is not distinguishable (Fig. 4). The Alfa Aesar powder (B, C) shows that a small oxide phase is present in the powder surface. The presence of oxides can lead to sintering problems and unexpected thermal conductibility and electric conductivity.

Table 3 summarizes the 4 Ss of the copper powder particles used in the present work. 
Table 3

Particle size, particle size distribution, shape, and surface (topography and structure)

\begin{tabular}{|llllll|}
\hline Powder & $\begin{array}{l}\text { Particle Size } \\
\mathrm{D}_{50}(\mu \mathrm{m})\end{array}$ & $\begin{array}{l}\text { Particle Size } \\
\text { distribution }\end{array}$ & $\begin{array}{l}\text { Shape } \\
\text { factor }\end{array}$ & Topography & Structure \\
\hline A & 28.00 & Bimodal & \pm 1 & $\begin{array}{l}\text { Uniform with some } \\
\text { satellites }\end{array}$ & $\begin{array}{l}\mathrm{Cu}+\text { traces } \\
\mathrm{Cu}_{2} \mathrm{O}\end{array}$ \\
\hline B & 11.30 & Unimodal & \pm 1 & $\begin{array}{l}\text { Uniform with some } \\
\text { satellites }\end{array}$ & $\mathrm{Cu}+\mathrm{Cu}_{2} \mathrm{O}$ \\
\hline C & 3.97 & Unimodal & \pm 1 & $\begin{array}{l}\text { Uniform with some } \\
\text { satellites }\end{array}$ & $\mathrm{Cu}+\mathrm{Cu}_{2} \mathrm{O}$ \\
\hline
\end{tabular}

\section{Experimental Methodology}

\subsection{Processing of Filaments Feedstocks}

\subsubsection{Evaluation of Critical Powder Volume Concentration (CPVC)}

The feedstocks were optimized in a torque rheometer (Plastograph ${ }^{\circledR}$ Brabender W 50, Brabender GmbH \& Co. KG, Duisburg, Germany) at a temperature of $180^{\circ} \mathrm{C}, 30 \mathrm{rpm}$ and a $38.5 \mathrm{~cm}^{3}$ mixing chamber. The strategy is to establish the best compromise between the maximum volume concentration of copper powder in the feedstock and its extrudability, which leads to the best conditions to extrude the filament without disruptions. This compromise is named critical powder volume concentration (CPVC) [24]. The optimum volume ratio has been widely studied in research works related to powder injection moulding (PIM). In the processing of filaments (extrusion), the methodology was similar, but the role of backbone and plasticizer needed to manufacture a filament must be highlighted. Figure 5 shows the methodology adopted for the optimization of copper powder volume concentration with a master binder.

Figure 5 shows the linear evolution of the feedstock torque as a function of the volume percentage of copper powder. Three different behaviours can be observed, as the powder percentage is increased. In general, the best solution for feedstock [24] corresponds to a concentration of $61 \mathrm{vol} . \%$ of powder (interception between the line of the medium slope with the maximum one). The concentration of 61 vol.\% was considered the maximum value for powder addition. After that point, the torque increases significantly, compromising the feedstock flowability, whatever the application.

\subsection{Shaping filaments}

After the evaluation CPVC feedstocks studied, they were granulated into small pellets and extruded in filament form, using a single screw extruder (Brabender GMBH\&Co. E 19/25 T without calibration system), with a nozzle of $1.75 \mathrm{~mm}$. The temperature in different zones of the extrusion cylinder were 170, 175 and $180^{\circ} \mathrm{C}$ (nozzle). 
In order to support the quality of filament for the additive process (MEX), function of powder characteristics, several tests of tensile and flexural strength were performed. The equipment was a Stable MicroSystems, Godalming, with a $5 \mathrm{kN}$ loading cell; tensile tests were carried a $0.5 \mathrm{~mm} / \mathrm{min}$ and a gauge length of $10 \mathrm{~mm}$, and for the three-point bending test the loading span was $20 \mathrm{~mm}$ and the cell load velocity of $0.5 \mathrm{~mm} / \mathrm{min}$. For both tests (tensile and bending), six specimens (green filament) were tested for each reference particle powder (A, B e C).

\subsection{MEX}

The filament was extruded in a Prusa i3 MK3S (Prusa Research, Prague, Czech Republic) through a 0.4 $\mathrm{mm}$ nozzle diameter. The nozzle temperature was $200^{\circ} \mathrm{C}$. The platform temperature was $50^{\circ} \mathrm{C}$ for the first layer and $80^{\circ} \mathrm{C}$ for the remaining layers. The print speed was $30 \mathrm{~mm} / \mathrm{s}$. The extrusion multiplier was set to 1.15 with the objective of offsetting the overlap and creating a more homogenous layer.

\subsection{Processing conditions after shaping \\ 4.4.1. Debinding}

The master binder and additives must be completely removed during the debinding step. The removal of the polymeric component is critical in the shaping, debinding and sintering (SDS) process. The type of debinding selected was based on thermal gravimetric analysis (TGA) of the filaments. During heating, the TGA curve highlights the temperatures where the loss of weight is disruptive, which means the temperatures where the organic constituents of feedstock are ustulated. The TGA curve representing the weight loss of the feedstock studied with temperature, in an inert atmosphere of $\mathrm{Ar}+\mathrm{H}_{2}\left(5 \mathrm{vol} . \% \mathrm{H}_{2}\right)$ and a heating rate of $1^{\circ} \mathrm{C} / \mathrm{min}$. From this curve, it is clear that the temperature of $500^{\circ} \mathrm{C}$ is enough to eliminate all the binder and additives of the feedstock ( $7.5 \%$ wt. $=39 \%$ vol.) (Fig. 6$)$.

Figure 7 shows the thermal cycle selected for an efficient debinding of the parts (brown). The conditions were the same used on the TGA, the atmosphere was $\mathrm{Ar}+\mathrm{H}_{2}\left(5 \mathrm{vol} . \% \mathrm{H}_{2}\right)$ and a heating rate of $1^{\circ} \mathrm{C} / \mathrm{min}$ was used.

\subsubsection{Sintering}

The brown parts were sintered in the same atmosphere of debinding, but the heating rate was $5^{\circ} \mathrm{C} / \mathrm{min}$ and the maximum temperature of $1045^{\circ} \mathrm{C}$, during $3 \mathrm{~h}$ (Fig. 8).

\subsubsection{Micrographic analysis of green and sintered filament}

The filament green was observed, without polishing and etching. However, after sintering, the specimens of filament were polished and chemically etched for optical microscopy analysis (Nikon OPTIHOT metallographic polarizing microscope). For the evaluation of the grain size (ASTM 407) and microstructure, the selected etchant was iron chloride, hydrochloric acid, water and Glycerol (1:1:3:5), during 1 minute. 


\section{Results And Discussion}

\subsection{Optimization of Feedstocks for Filaments based on copper powder}

For the development of a new copper filament for MEX (Material Extrusion), several feedstocks were developed using torque rheometry equipment. CPVC (critical powder volume concentration) was 61 vol.\% [25]. Table 4 shows the final composition of each feedstock, with its associated torque.

Table 4 - Composition of feedstocks and Torque

\begin{tabular}{|lllll|}
\hline Feedstock & Cu (vol.\%) & Binder + additive (vol.\%) & $\rho\left(\mathrm{Kg} / \mathrm{m}^{3}\right)$ & Torque (N.m) \\
\hline A & 61 & 39 & 5345 & 3.8 \\
\hline B & 61 & 39 & 5330 & 5.1 \\
\hline C & 61 & 39 & 5205 & 4.4 \\
\hline
\end{tabular}

An increase in torque and instability was observed In the mixture of powder with finer particles. This is related to the fact that the smaller the particle size, the larger the specific contact surface area, promoting friction between particles [26, 27]. By keeping the same powder, it would be possible to lower the value of the torque by decreasing the vol. \% powder in the mixture, however, the aim is to produce mixtures keeping the optimal vol. \% of powder, to produce filaments with suitable characteristics for processing by MEX.

\subsection{Green}

\subsubsection{Filaments}

The extruded filaments, all produced under the same conditions, have variations in diameter depending on the mixture, with the filaments $A-1.76 \mathrm{~mm}, \mathrm{~B}-1.70 \mathrm{~mm}$ and $\mathrm{C}-1.68 \mathrm{~mm}$. The variation along the filament is not significant, being negligible.

The filaments were analysed concerning homogeneity (distribution of Cu powder particles and polymeric material). Figure 9 to 11 show micro-CT and SEM images of each type of filament. Filament A shows small pores distributed randomly throughout its volume, which can be a resultant of the influence of the large size distribution, which severely affects the powder behaviour during extrusion since particle mobility is highly dependant on particle size. Filament $B$ is an almost ideal case, since there is a uniform distribution and low interparticular distance, with no discernible defects, within the micro-CT resolution. Filament $\mathrm{C}$ shows random pores, even though less prevalent and smaller than in filament $\mathrm{A}$, but SEM images indicate apparent high mobility of the binder and additives. This low wettability can severely affect the sintering and debinding dynamics. Micro-CT volume rendering of the filaments reveals low to no ovality on the different filaments and a constant diameter. 
After detailed analyses of the filament morphology, tensile tests (Fig. 12) and flexural tests (Fig. 13) were performed. The mechanical characterization revealed that specimen A had more fragile behaviour than the others in the tensile tests, consistent with the porosity throughout the filament volume. As expected, the tensile strength is the highest for specimen $B(12.1 \mathrm{MPa})$, followed by the $C$ filament with $10.9 \mathrm{MPa}$ and with the lower value A with 7.6 MPa. This decrease seems to be influenced by particle size. Young modulus shows a higher value for specimen B (2.2 GPa). The mechanical results support the detailed analysis made by micro-CT. Flexural tests revealed that the filament that could withstand the highest deflection was the filament with higher homogeneity and fewer defects, B. Even so, the behaviour of the flexural modulus is very similar for the three different filaments. The high deflection at break and low flexural modulus combo was proven to be printable by [25].

\subsubsection{Strands}

The strands, subsequent to printer extrusion, were evaluated to analyze the influence of the small nozzle orifice (diameter $=400 \mu \mathrm{m}$ ) on the distribution of the powder, which will be organized similarly in the final part. The micro-CT analysis for the whole volume of the filament was confirmed using SEM. In the first case, powder A, resultant in a non-uniform strand, with bigger particles randomly organized throughout the volume, this can be seen in the micro-CT (high-density particles with a diameter bigger than the lower resolution - $5.67 \mu \mathrm{m}$ - in white) and the SEM image. Filament strand B, even though a low wettability of the binder + additives can be observed, has a very good distribution of the powder and interparticular distance, as seen in original filament form. Strand $C$ suggests that small defects, enlarged in the extrusion direction may appear during printing, and may be caused by the small hole diameter and small particle compaction behaviour.

\subsubsection{D object after printing}

Micro-CT of the green parts was made to observe the influence of each filament on the quality of a final part produced with the same optimal parameters. Since copper is a dense material, which affects the $x-$ ray behaviour on micro-CT, only large pores were considered for this observation. Part A has a large number of defects that start halfway through construction, and a large open pore resultant from the use of spiral printing strategy. This may be the result of the lack of nozzle to heatbed pressure, which obliges the strands to be flattened against the surface since the distance between the nozzle and substrate is not the same as each strand height. Like the filament, part B seems to have no apparent defects and presents a better geometrical accuracy than part A. Part $\mathrm{C}$ also shows high density, but the micro-CT suggests that small defects may be present in the centre of the part. This may suggest that the extrusion multiplier parameter may be creating enough pressure to mitigate the lack of the density apparent in each filament strand.

The observation of the XRD of the green 3D objects shows that no apparent oxidation occurred in the printing step, which is highly important to the sinterability of the copper objects.

\subsection{Filaments after debinding and sintering}


To prove the sinterability of the copper feedstocks and to avoid the influence of printing parameters in the final density, the three different filaments were debinded and sintered. Figure 21 to 23 show a micro-CT and a photo of the sintered filament. Sintered filaments A and B show the same defects seen in the green filaments and demonstrate the sinterability of the two copper powder sizes. Sintered filament $C$ has different behaviour. The external part of the filament is sintered and the central part has a low density, which means it is not sintered. This can be due to some copper oxide present in filament $\mathrm{C}$ resulted in a barrier to the sintering of the central part. Further discussion is shown on the metallography of the filaments.

Table 5 summarizes different microhardness values measured in bulk copper and MEX 3D sintered objects, from powder $\mathrm{A}, \mathrm{B}$ and $\mathrm{C}$ for the same thermal treatment (debinding and sintering) conditions. The microhardness values are higher than the hardness of the bulk copper sample $( \pm 21 \mathrm{HV})$. These values are in agreement to the presence of $\mathrm{Cu}_{2} \mathrm{O}[28]$.

Table 5 - Ultra microhardness of the sintered filament

\begin{tabular}{|lllll|}
\hline Specimen & Copper (bulk) & A & B & C \\
\hline Microhardness $\left(\mathrm{HV}_{0.1}\right)$ & $21 \pm 1.2$ & $68 \pm 8.9$ & $65 \pm 2.7$ & $80 \pm 2.3$ \\
(10 measurements) & & & & \\
\hline
\end{tabular}

\subsection{Microstructures}

Figure 25 shows different representative metallographies of sintered copper MEX filaments. They highlight the role of particles powder size in their sinterability. All the sintered filaments present a typical microstructure of copper. However, is clear that $A$ and $C$ present a significant porosity, $A$ with higher porosity than $\mathrm{C}$. However, the difficulty of sintering evident in micro-CT for sintered $\mathrm{C}$ is due to the powder oxidation, referred to before.

\section{Conclusions}

The production of copper 3D objects by direct additive manufacturing, particularly those associated with the liquid state (SLM), entails several problems that can be overcome with the indirect MEX technology. According to the available literature, no studies have investigated the influence of copper powder particles characteristics on the products made by MEX technology. It is, therefore, crucial to have a complete understanding of all five steps involved in the manufacturing process, namely: mixing the constituents of the filaments (copper powder, binder and additives), extrusion (filament manufacturing), printing (3D object moulding), debinding (binder removal), and sintering (powder particle consolidation).

Highly filled composite materials have been prepared with $61 \mathrm{vol} \%$ of copper with three different particle size and particle size distributions. It was concluded that the filaments were successfully extruded with a homogeneous distribution of powder, binder and additives, particularly considering the absence of pressure effect during extrusion. Moreover, it became evident that the green filament based on powder B 
has the maximum strength and deflexion at break. After debinding and sintering the best filament (B) has a $D_{50}$ close to $11 \mu \mathrm{m}$ with a monomodal particle size distribution, shape factor 1 and a surface similar to other powder. The only negative aspect of copper, that must be overcome in MEX, is the powder oxidation, resulting from powder preparation, which depends of particle size, and it is evident by the density values of copper powder. This negative aspect, which has consequences in sintering must be overcome by the selection of another environmental atmosphere than $\mathrm{Ar}+\mathrm{H} 2$, for example by $\mathrm{H}_{2}$ [29].

\section{Declarations}

Funding This work was supported by the European Regional Development Fund (ERDF) under the Portuguese program-Programa Operacional Factores de Competitividade (COMPETE) [grant agreement No. POCI-01-0247-FEDER-024533]; and this research is sponsored by FEDER funds through the program COMPETE - Programa Operacional Factores de Competitividade - and by national funds through FCT Fundação para a Ciência e a Tecnologia , under the project UIDB/00285/2020 and UIDB/04044/2020.

Conflicts of interest The authors declare that they have no conflict of interest.

Availability of data and material Data will be available upon request.

Ethical approval Not applicable.

Consent to participate Not applicable.

Consent for publication Not applicable

\section{References}

1. Singh S, Ramakrishna S, Singh R (2017) Material issues in additive manufacturing: A review. Journal of Manufacturing Processes 25:185-200. https://doi.org/10.1016/j.jmapro.2016.11.006

2. Ngo TD, Kashani A, Imbalzano G, et al (2018) Additive manufacturing (3D printing): A review of materials, methods, applications and challenges. Composites Part B: Engineering 143:172-196. https://doi.org/10.1016/j.compositesb.2018.02.012

3. J. Gonzalez-Gutierrez, D. Godec, R. Guráň, et al (2018) 3D printing conditions determination for feedstock used in fused filament fabrication (FFF) of 17-4PH stainless steel parts. Metalurgija 57:117-120

4. Orlovská M, Chlup Z, Bača L', et al (2020) Fracture and mechanical properties of lightweight alumina ceramics prepared by fused filament fabrication. Journal of the European Ceramic Society 40:48374843. https://doi.org/10.1016/j.jeurceramsoc.2020.02.026

5. Thompson Y, Gonzalez-Gutierrez J, Kukla C, Felfer P (2019) Fused filament fabrication, debinding and sintering as a low cost additive manufacturing method of $316 \mathrm{~L}$ stainless steel. Additive Manufacturing 30:100861. https://doi.org/10.1016/j.addma.2019.100861 
6. ISO/ASTM Additive manufacturing - General principles - Terminology (ISO/ASTM DIS 52900:2018)

7. Randall M. German, Animesh Bose (1997) Injection Molding of Metals and Ceramics. Metal Powder Industry, Princeton, N.J.

8. Goudah G, Ahmad F, Mamat O, Omar MohdA (2010) Preparation and Characterization of Copper Feedstock for Metal Injection Molding. J of Applied Sciences 10:3295-3300.

https://doi.org/10.3923/jas.2010.3295.3300

9. Hausnerova B, Kitano T, Kuritka I, et al (2011) The Role of Powder Particle Size Distribution in the Processability of Powder Injection Molding Compounds. International Journal of Polymer Analysis and Characterization 16:141-151. https://doi.org/10.1080/1023666X.2011.547047

10. S. Riecker, J. Clouse, T. Studnitzky, et al (2016) Fused Deposition Modeling-Opportunities for cheap metal AM. In: European Congress and Exhibition on Powder Metallurgy. European PM Conference Proceedings. EPMA, Hamburg, Germany

11. N. Cruz, L. Santos, J. Vasco, F.M. Barreiros (2013) Binder System for Fused Deposition of Metals. In: Proceedings of the Euro PM2013, Congress \& Exhibition. EPMA, Gothenburg, Sweden, pp 79-84

12. Kukla C, Gonzalez-Gutierrez J, Duretek I, et al (2017) Effect of particle size on the properties of highlyfilled polymers for fused filament fabrication. Lyon, France, p 190006

13. Khatri B, Lappe K, Noetzel D, et al (2018) A 3D-Printable Polymer-Metal Soft-Magnetic Functional Composite-Development and Characterization. Materials 11:189. https://doi.org/10.3390/ma11020189

14. Dehdari Ebrahimi N, Ju YS (2018) Thermal conductivity of sintered copper samples prepared using 3D printing-compatible polymer composite filaments. Additive Manufacturing 24:479-485. https://doi.org/10.1016/j.addma.2018.10.025

15. El-Wardany TI, She Y, Jagdale VN, et al (2018) Challenges in Three-Dimensional Printing of HighConductivity Copper. Journal of Electronic Packaging 140:020907. https://doi.org/10.1115/1.4039974

16. Lykov PA, Safonov EV, Akhmedianov AM (2016) Selective Laser Melting of Copper. Materials Science Forum 843:284-288. https://doi.org/10.4028/www.scientific.net/MSF.843.284

17. Trevisan F, Calignano F, Lorusso M, et al (2017) Selective laser melting of chemical pure copper

18. Silbernagel C, Gargalis L, Ashcroft I, et al (2019) Electrical resistivity of pure copper processed by medium-powered laser powder bed fusion additive manufacturing for use in electromagnetic applications. Additive Manufacturing 29:100831. https://doi.org/10.1016/j.addma.2019.100831

19. Ikeshoji T-T, Nakamura K, Yonehara M, et al (2018) Selective Laser Melting of Pure Copper. JOM 70:396-400. https://doi.org/10.1007/s11837-017-2695-x

20. Colopi M, Caprio L, Demir AG, Previtali B (2018) Selective laser melting of pure Cu with a $1 \mathrm{~kW}$ single mode fiber laser. Procedia CIRP 74:59-63. https://doi.org/10.1016/j.procir.2018.08.030

21. Jadhav SD, Dadbakhsh S, Goossens L, et al (2019) Influence of selective laser melting process parameters on texture evolution in pure copper. Journal of Materials Processing Technology 270:47- 
58. https://doi.org/10.1016/j.jmatprotec.2019.02.022

22. (2017) BASF launches Ultrafuse 316LX for fused filament fabrication of metal parts. In: Metal Additive Manufacturing. https://www.metal-am.com/basf-launches-ultrafuse-316lx-fused-filamentfabrication-metal-parts/. Accessed 18 Apr 2021

23. T.J. Ferreira, M.T. Vieira (2017) Optimization of MWCNT - Metal Matrix Composites feedstocks. Ciência \& Tecnologia dos Materiais 29:87-91. https://doi.org/10.1016/j.ctmat.2016.07.010

24. Telma Joana Jesus Ferreira (2018) Microinjection Moulding of Austenitic Stainless Steel Reinforced with Carbon Nanotubes. PhD Thesis, University of Coimbra

25. Fábio Cerejo, Daniel Gatões, M. T. Vieira (2021) Optimization of Metallic Powder Filaments for Additive Manufacturing Extrusion (MEX). https://doi.org/10.21203/rs.3.rs-168766/v1

26. Ibrahim MHI, Muhamad N, Sulong AB (2011) Rheological Characterization of Water Atomised Stainless Steel SS316L for Micro MIM. Advanced Materials Research 264-265:129-134. https://doi.org/10.4028/www.scientific.net/AMR.264-265.129

27. Sotomayor ME, Várez A, Levenfeld B (2010) Influence of powder particle size distribution on rheological properties of 316L powder injection moulding feedstocks. Powder Technology 200:3036. https://doi.org/10.1016/j.powtec.2010.02.003

28. Strąk C, Olesińska W, Siedlec R Influence of carbon and oxygen on properties of Cu-C-O composites. Electronic Materials 13

29. Hao H, Wang Y, Jafari Nodooshan HR, et al (2019) The Effects of Sintering Temperature and Addition of $\mathrm{TiH} 2$ on the Sintering Process of $\mathrm{Cu}$. Materials 12:2594. https://doi.org/10.3390/ma12162594

\section{Figures}

Feedstock mixture

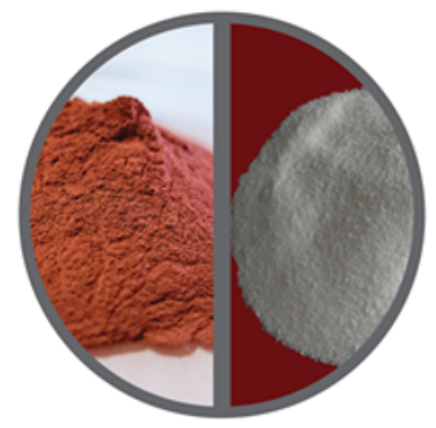

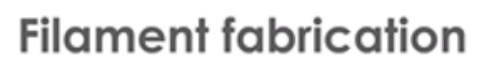

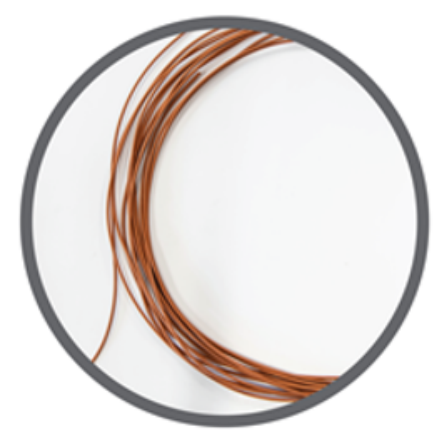

Shape

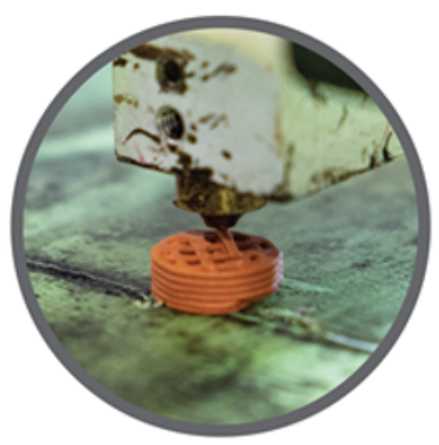

Debinding

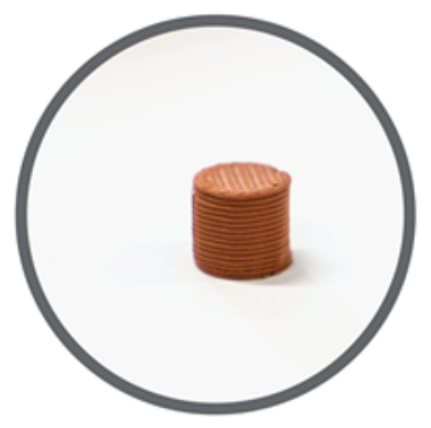

Sintering

\section{Figure 1}

Steps in the MEX process 


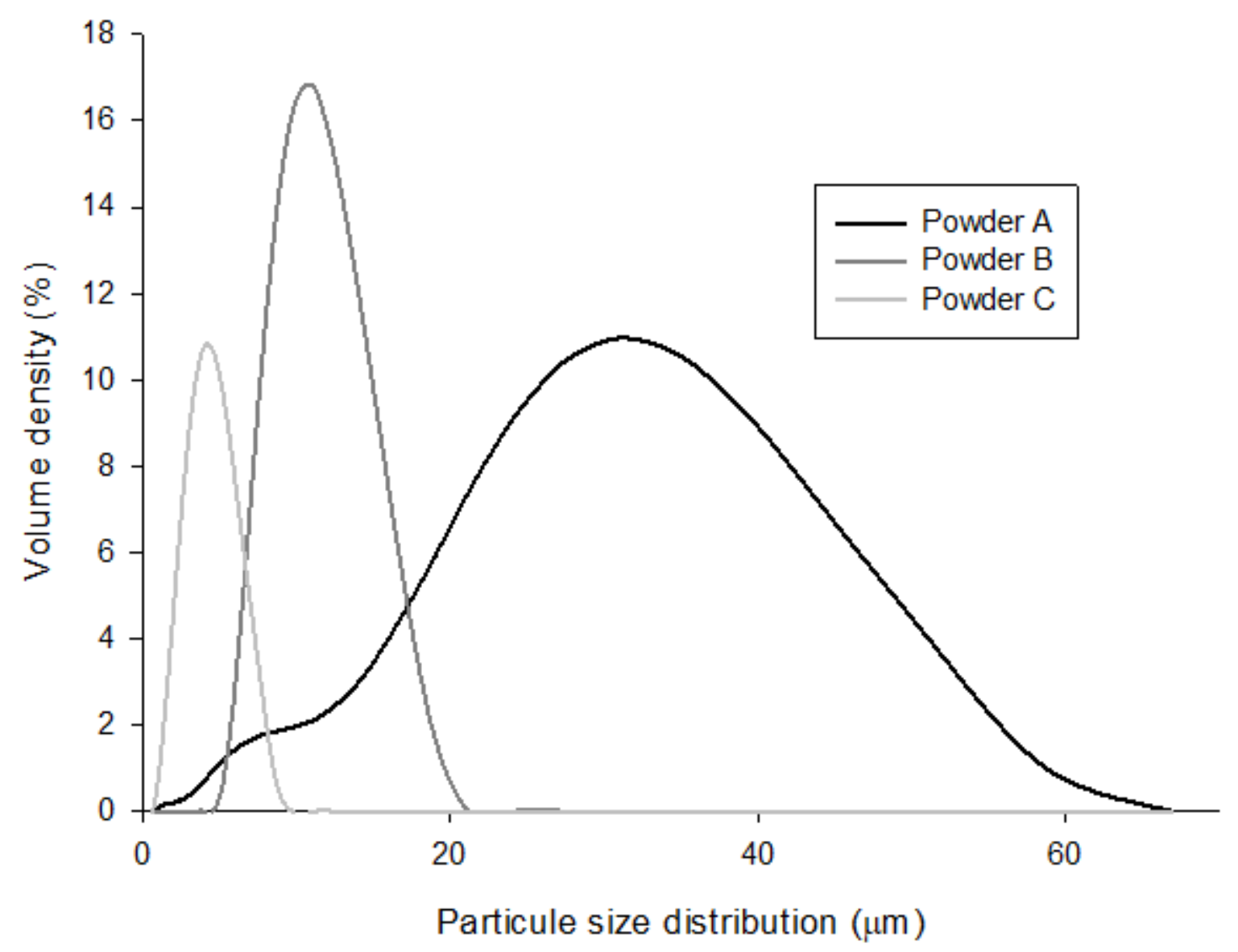

Figure 2

Particle size distribution of copper powder. 

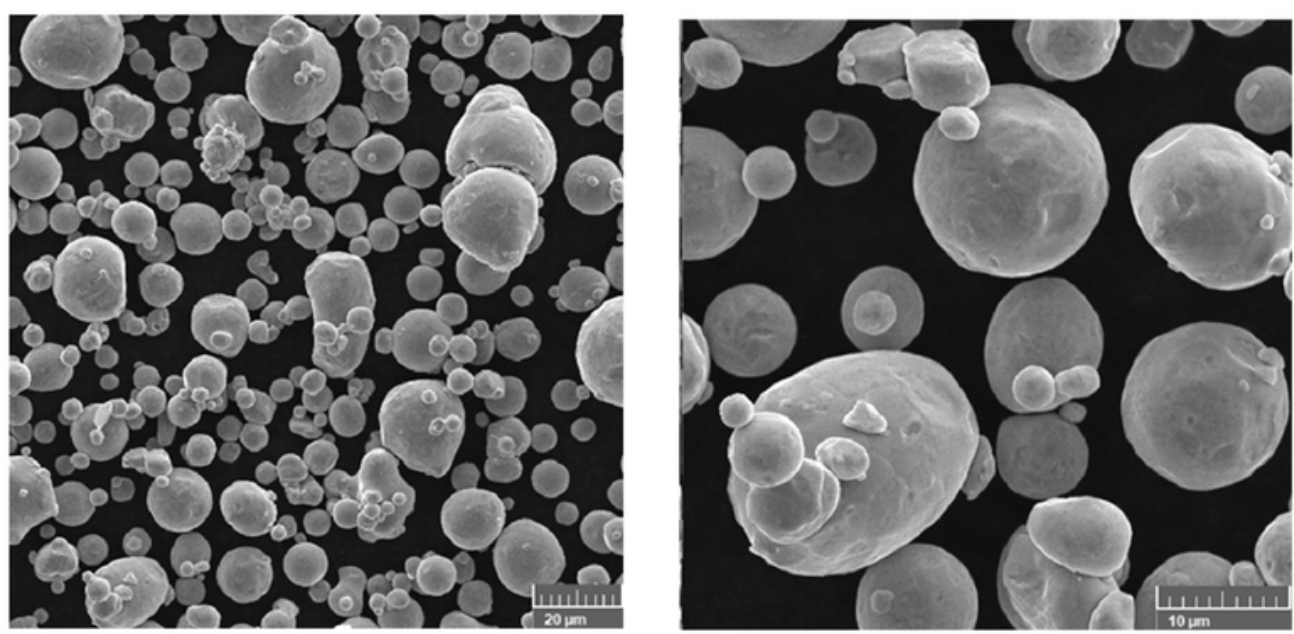

(a)
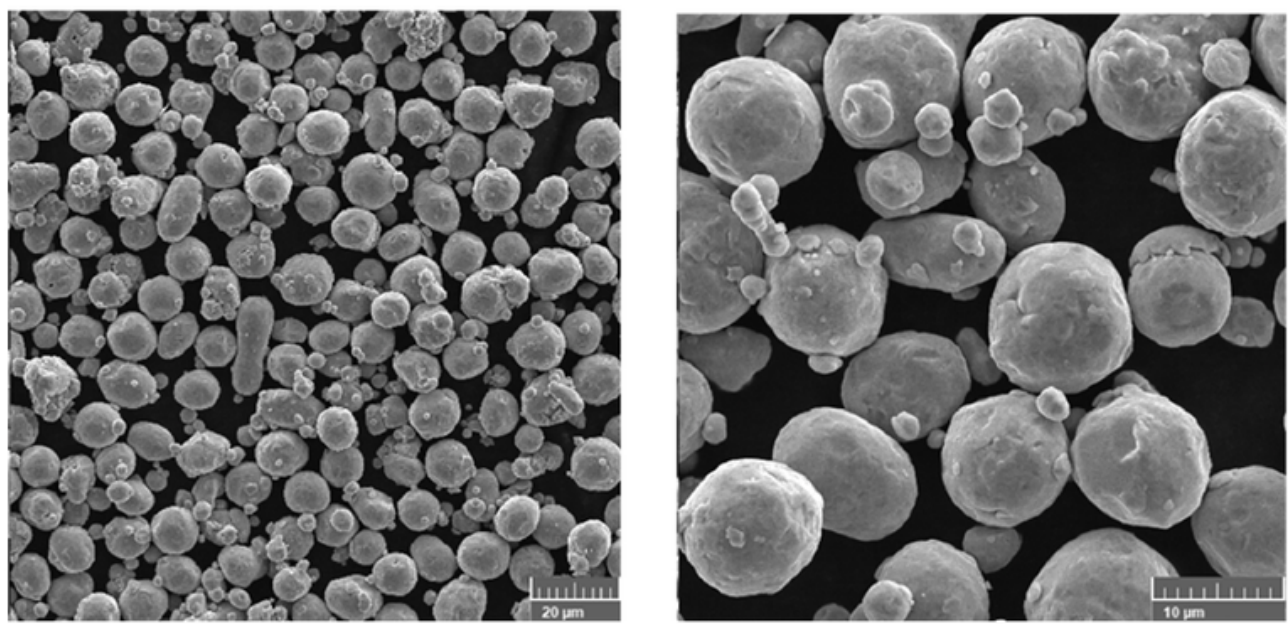

(b)
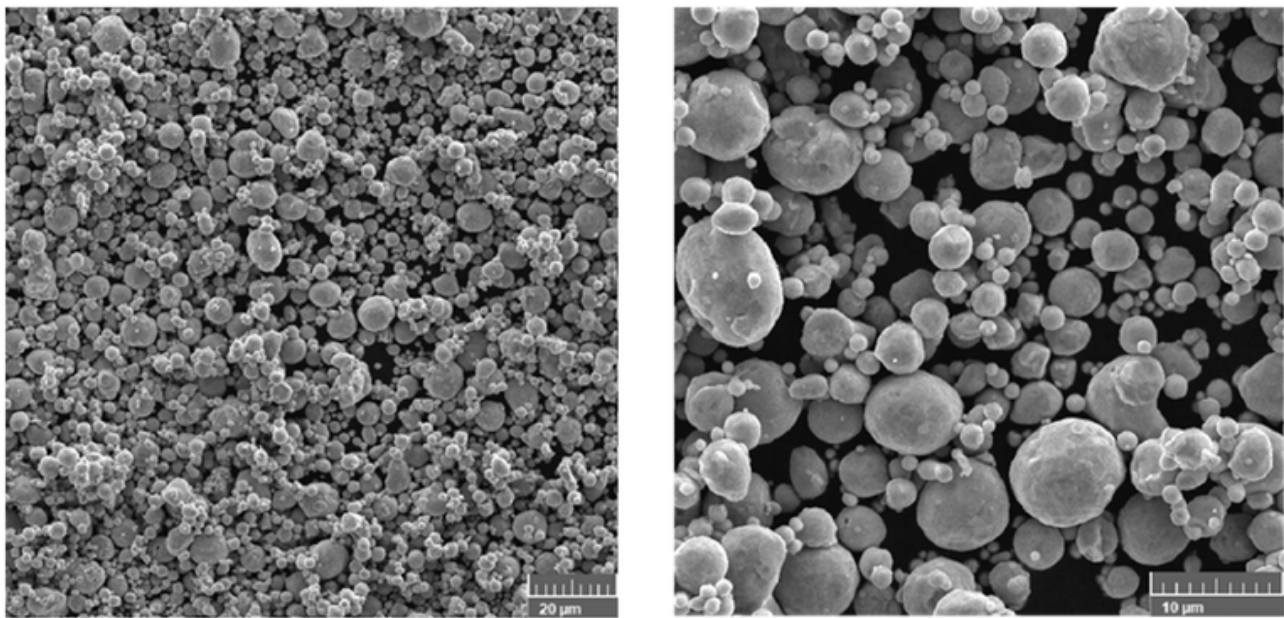

(c)

Figure 3

Particle powder morphology (SEM) (a) powder A, (b) powder B and (c) powder C 


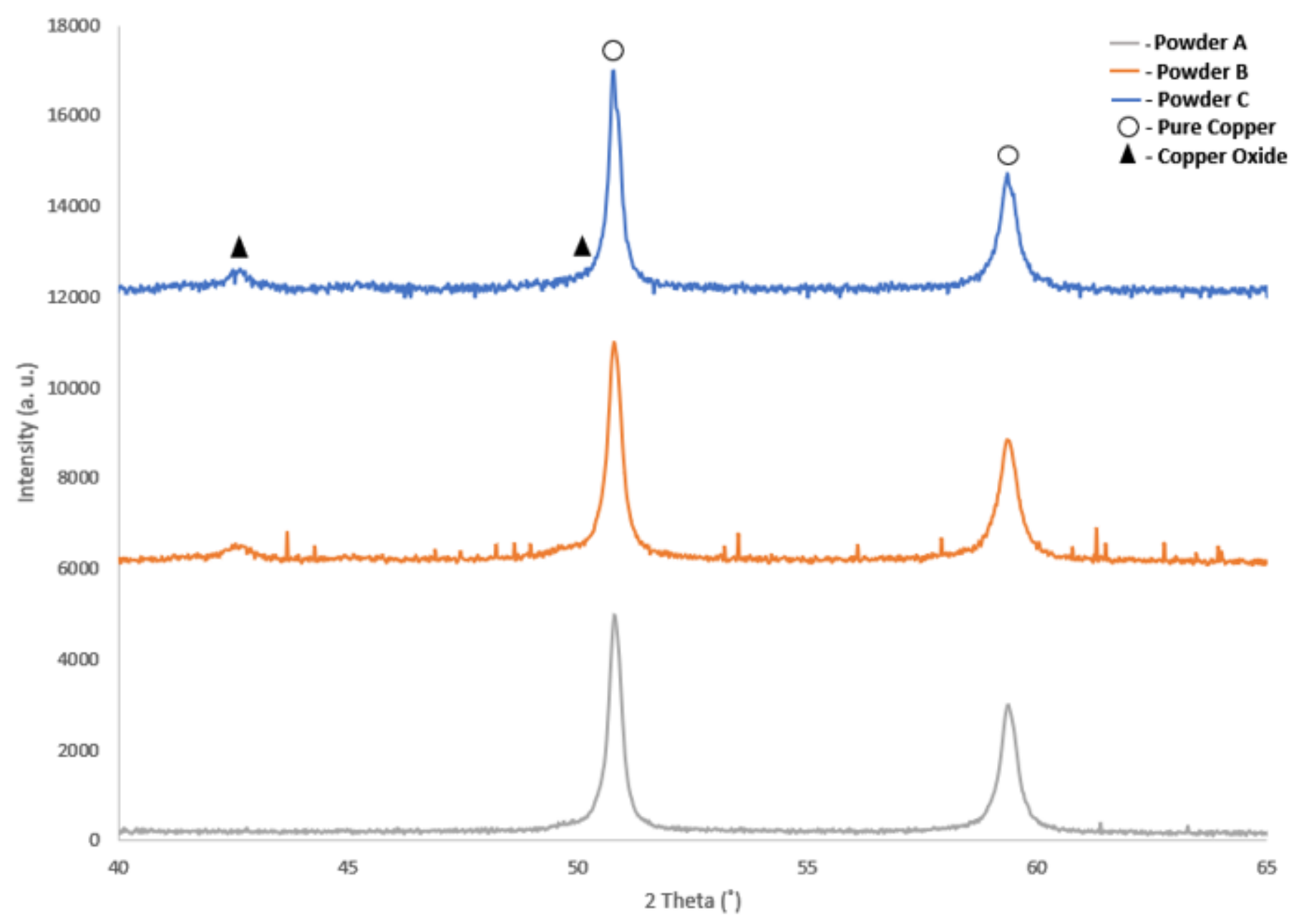

Figure 4

Copper powder X-ray diffraction of (bottom) powder A, (middle) powder B and (top) powder C 


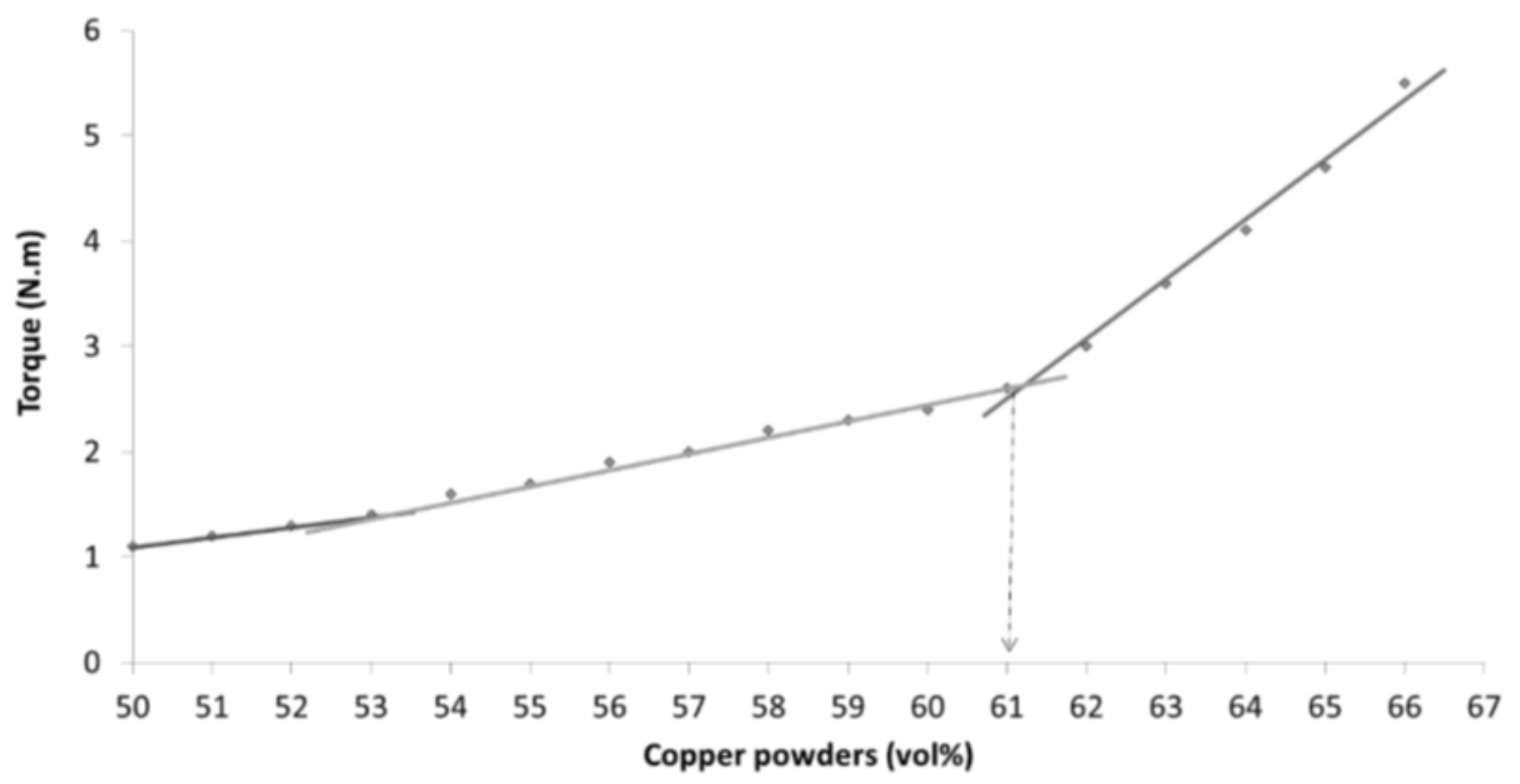

Figure 5

Copper + master binder feedstock optimization [24].

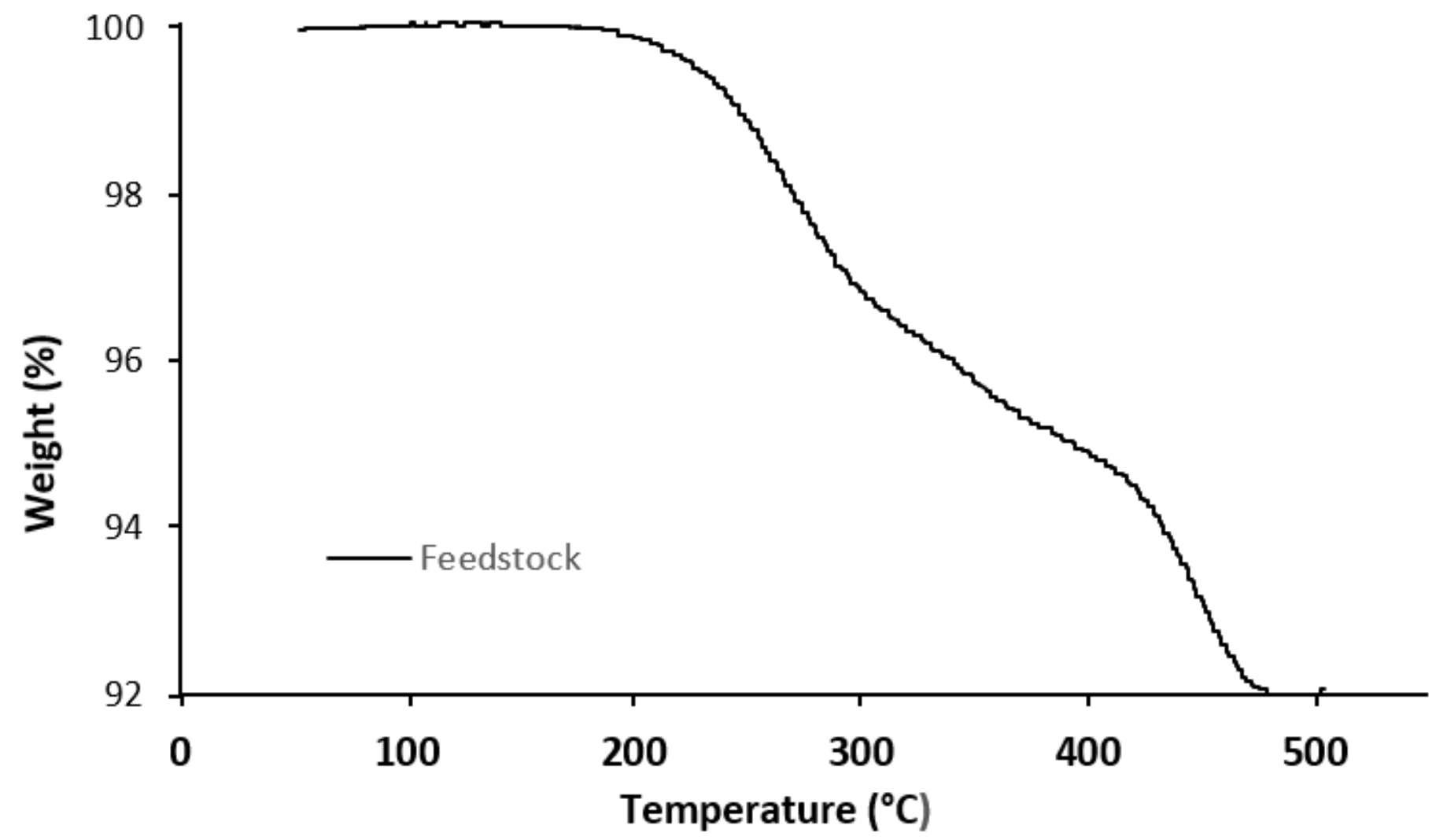

Figure 6 


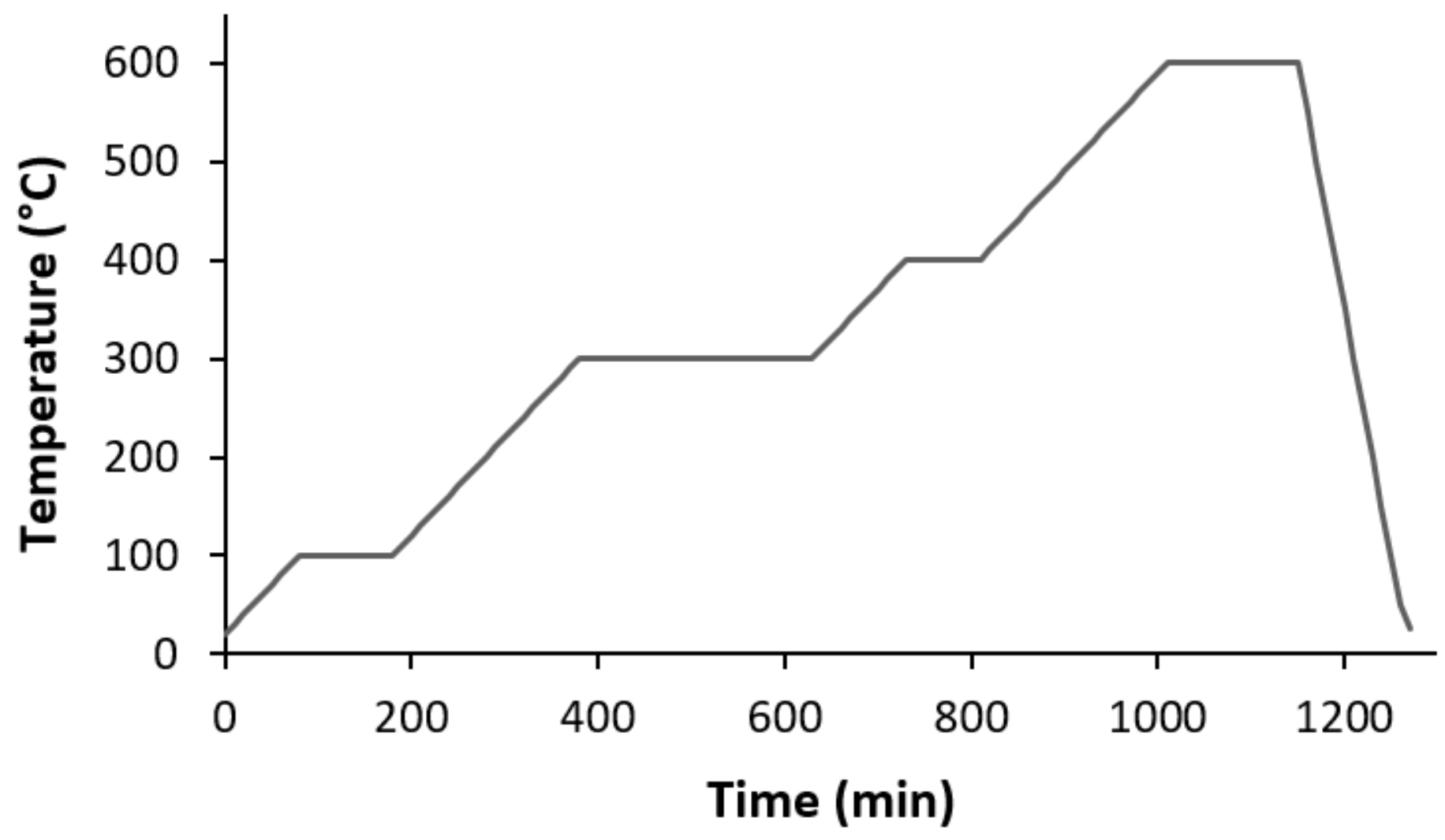

Figure 7

Thermal debinding cycle 


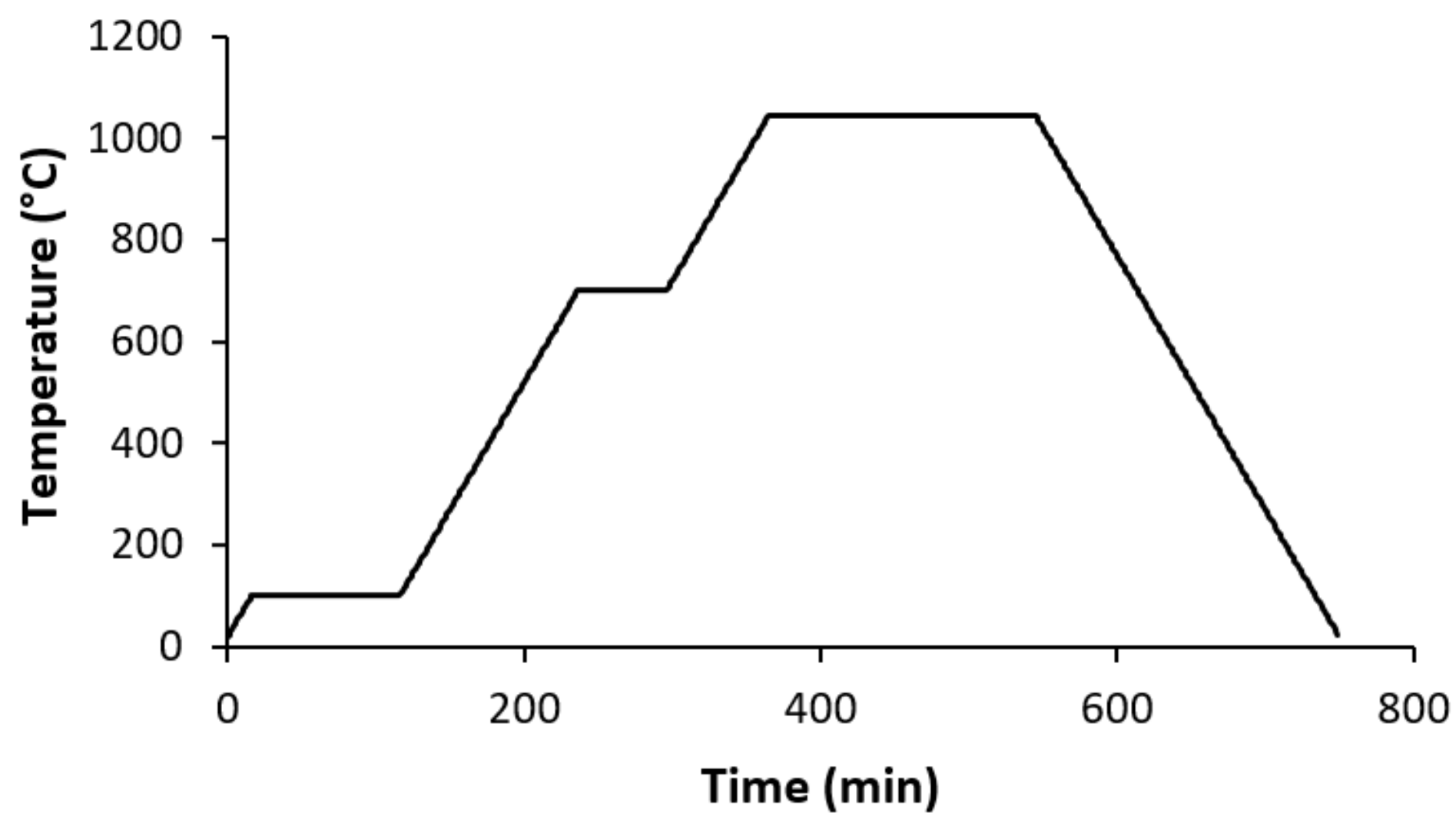

Figure 8

Thermal sintering cycle 


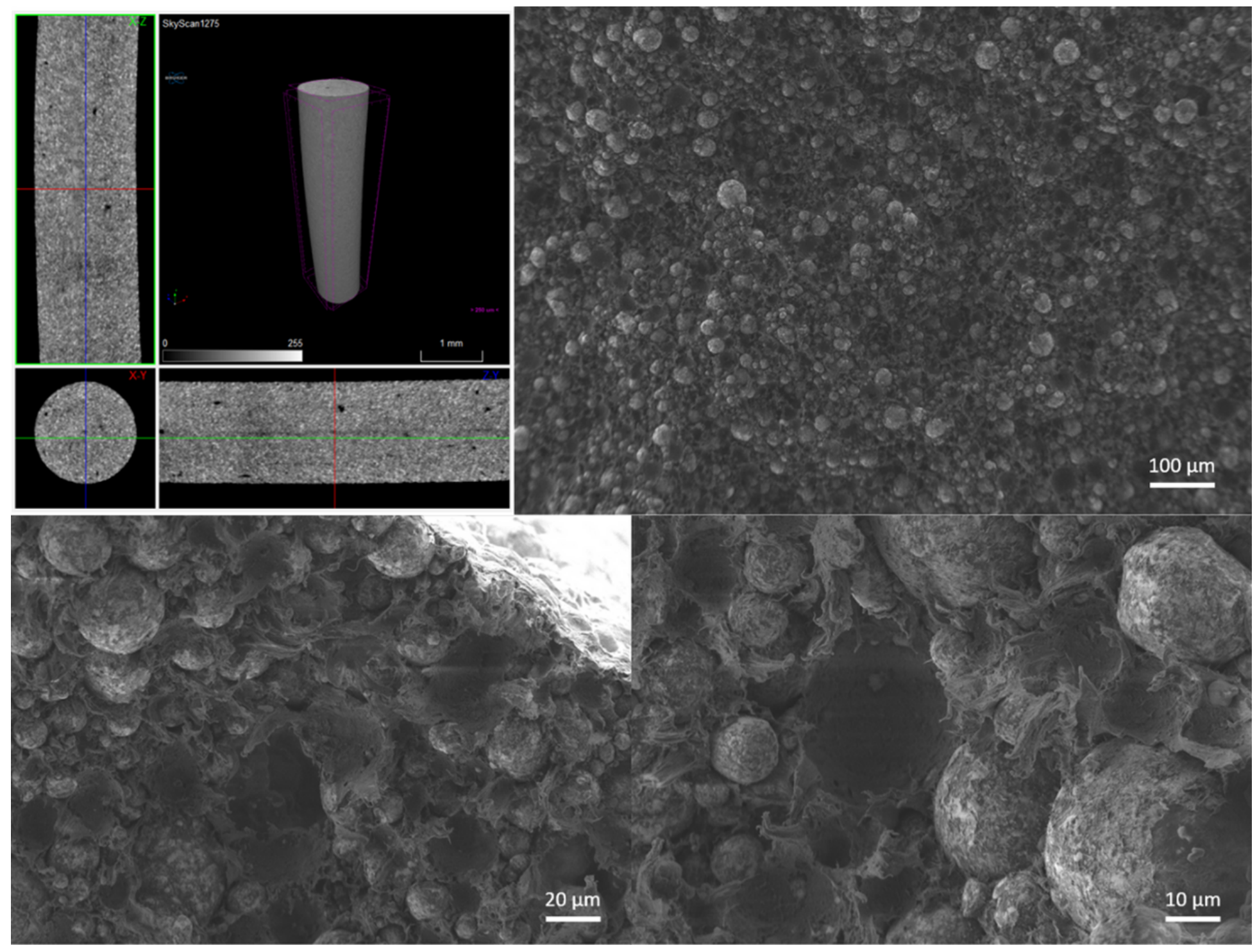

\section{Figure 9}

Filament A green (a) micro-CT; (b) feedstock (SEM) (100x); (c) (500x) and (d) (1000x). 


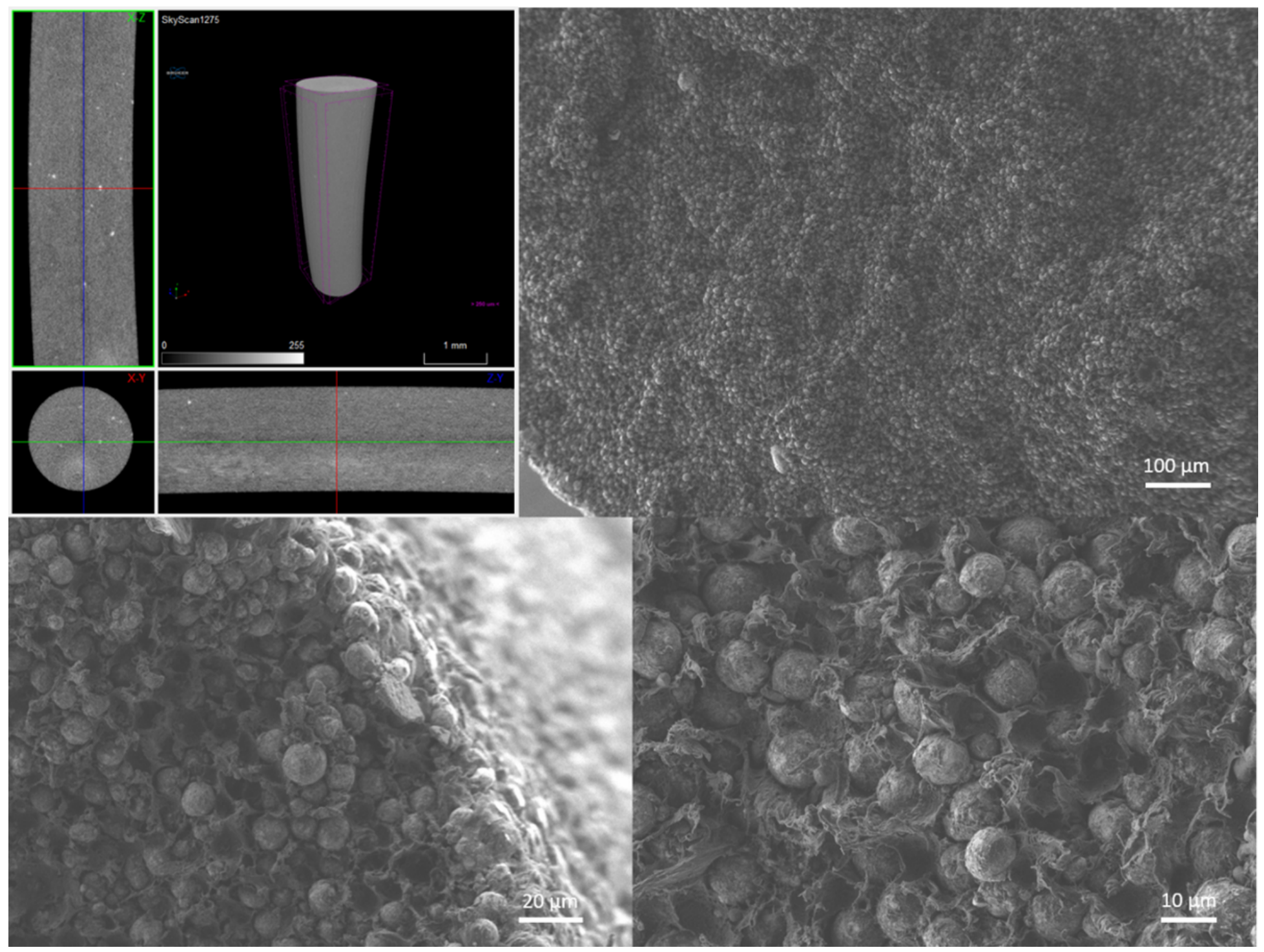

Figure 10

Filament B green (a) micro-CT; (b) feedstock (SEM) (100x); (c) (500x) and (d) (1000x). 

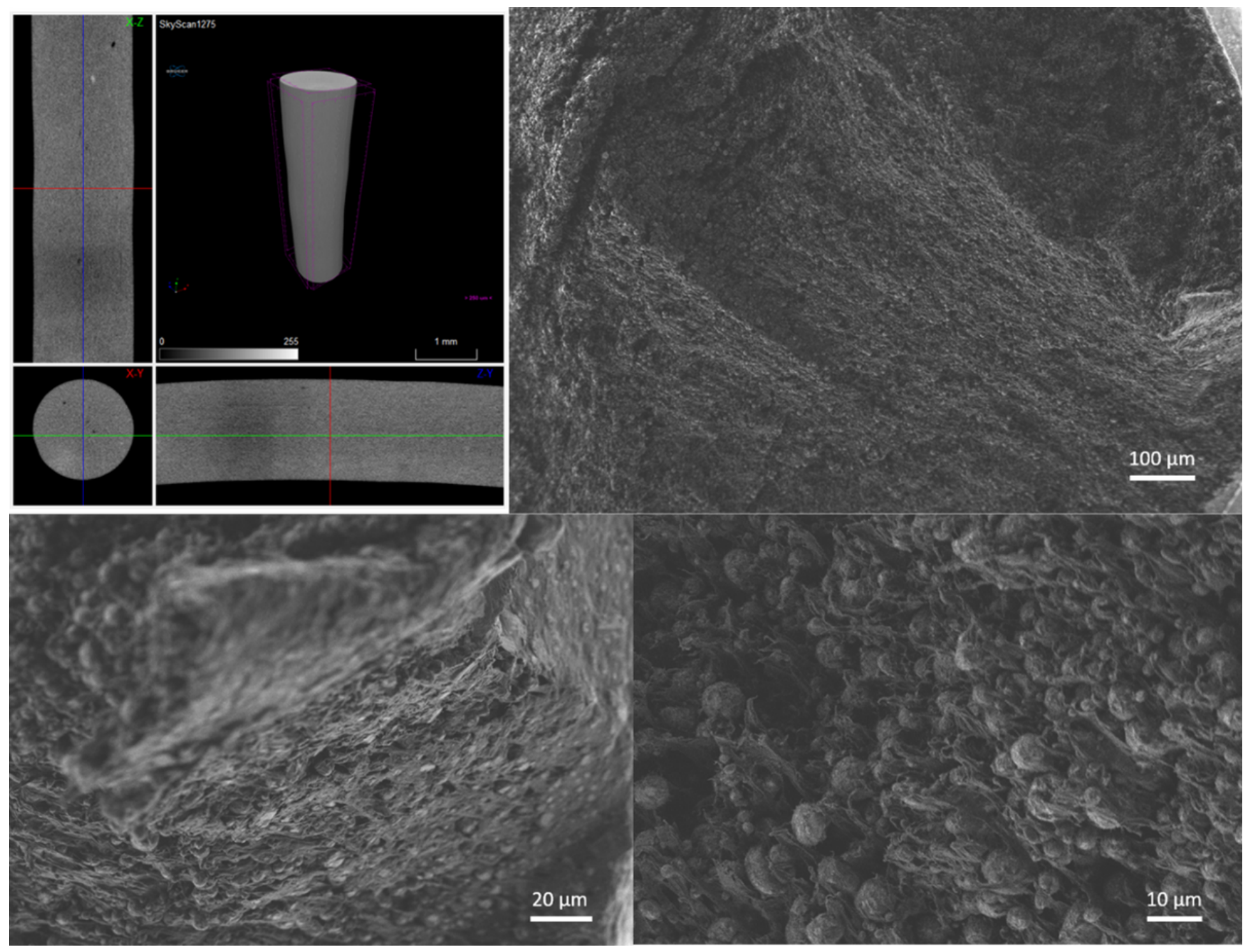

Figure 11

Filament C green (a) micro-CT; (b) feedstock (SEM) (100x); (c) (500x) and (d) (1000x). 

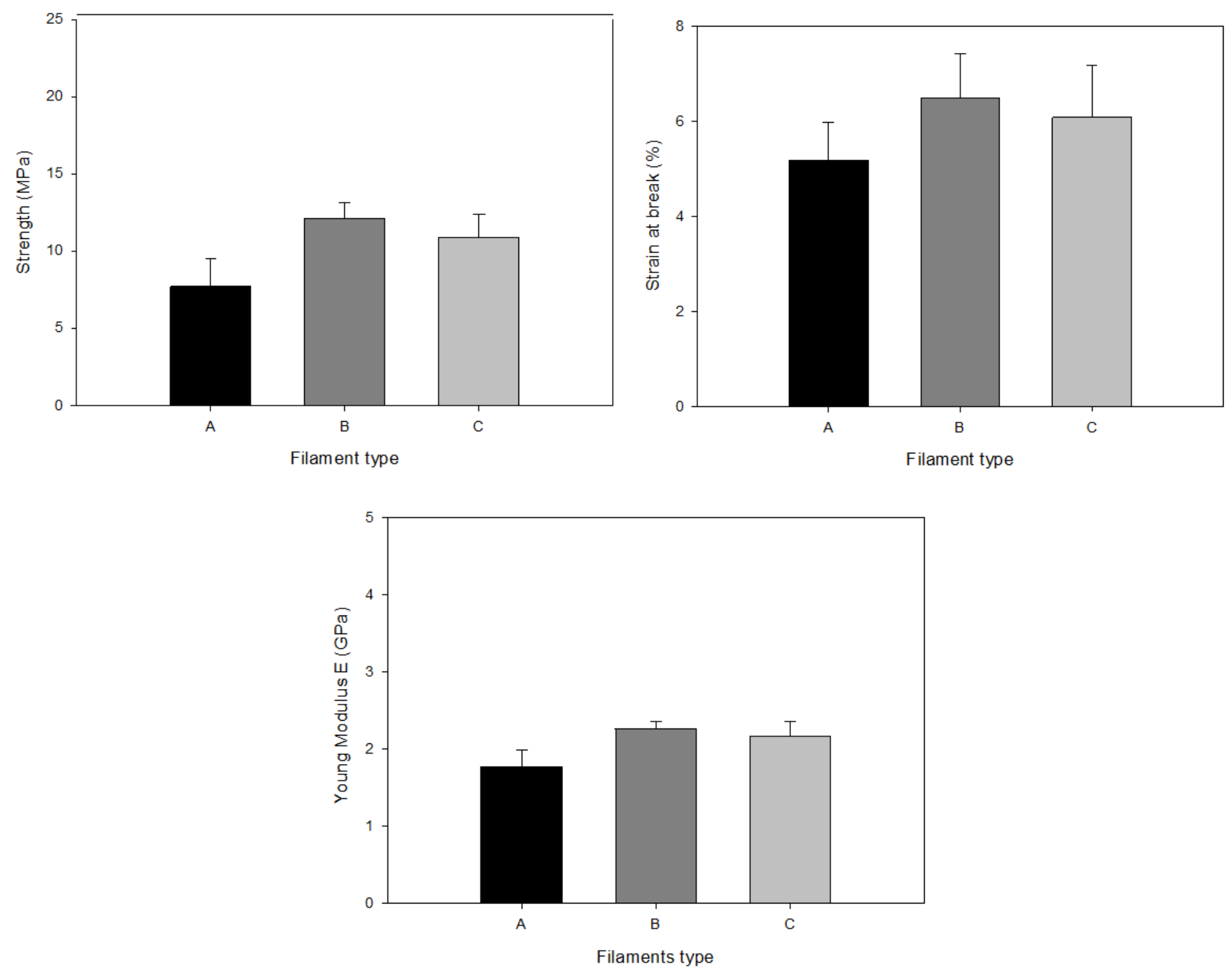

Figure 12

Tensile Test 

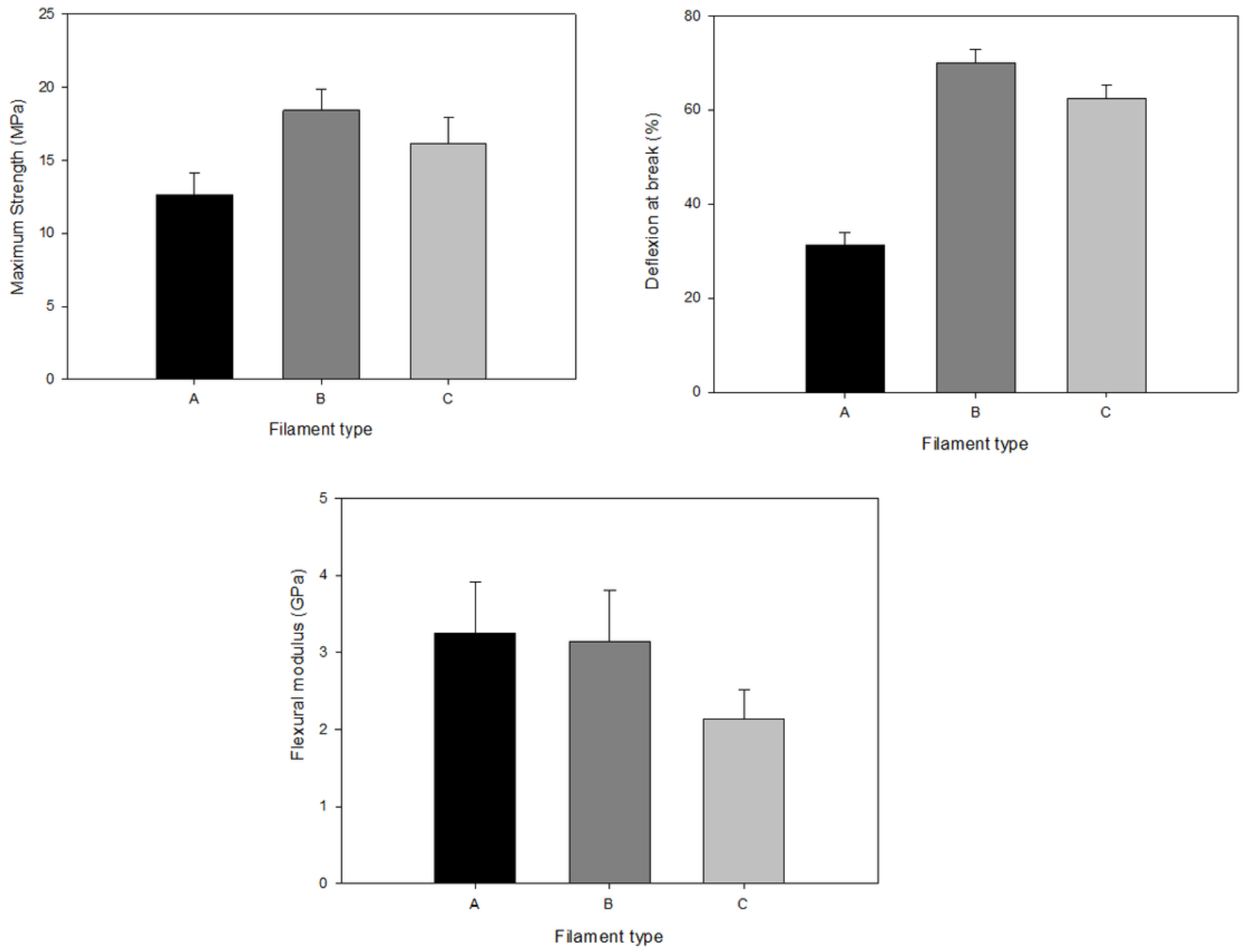

Figure 13

Three-point bending test
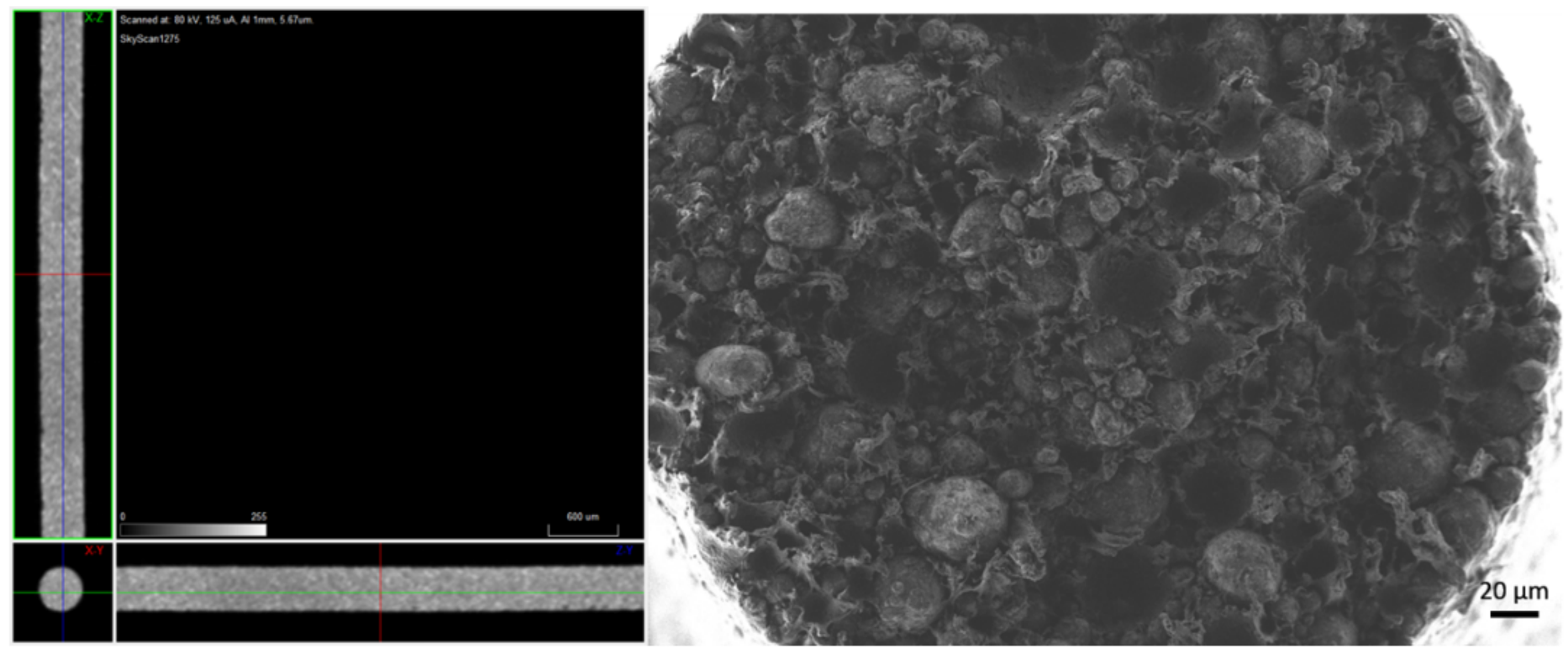
Figure 14

Strand A (a) micro-CT; (b) SEM
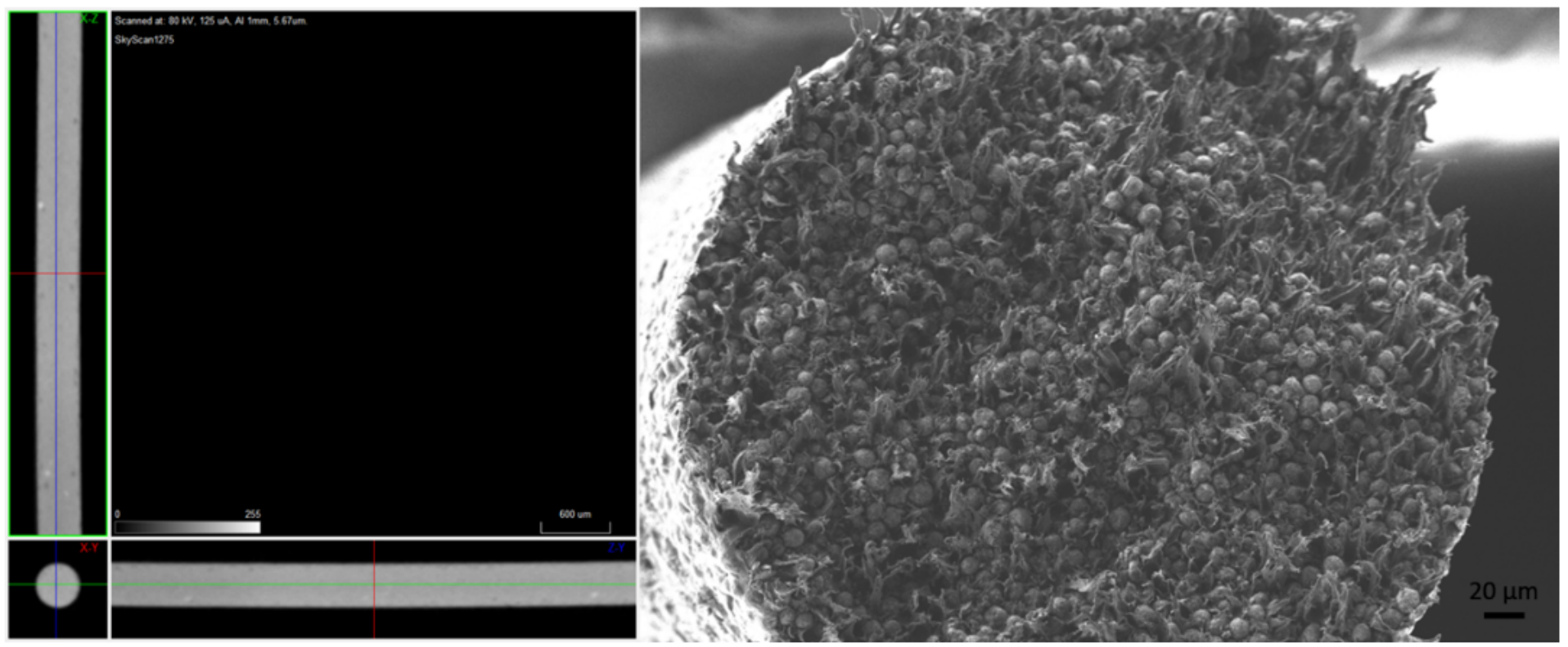

Figure 15

Strand B (a) micro-CT; (b) SEM
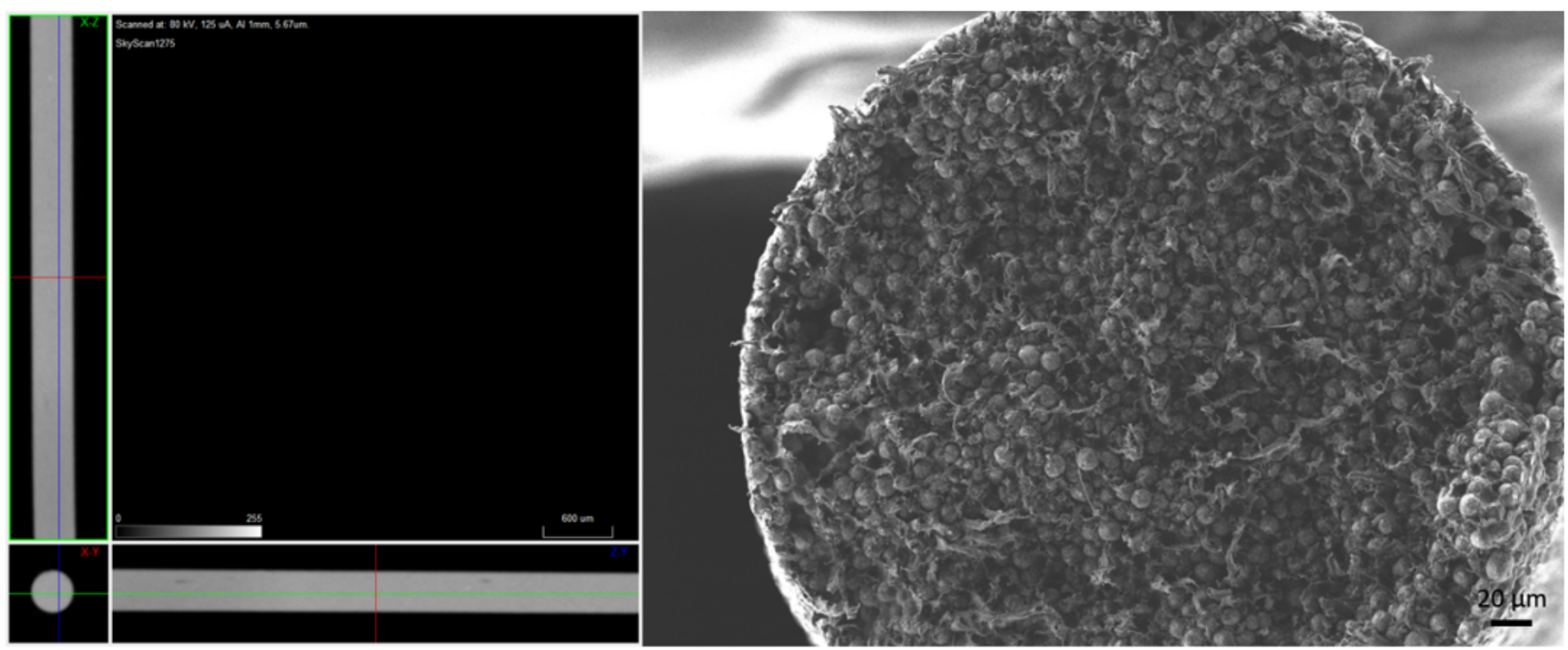

Figure 16

Strand C (a) micro-CT; (b) SEM. 

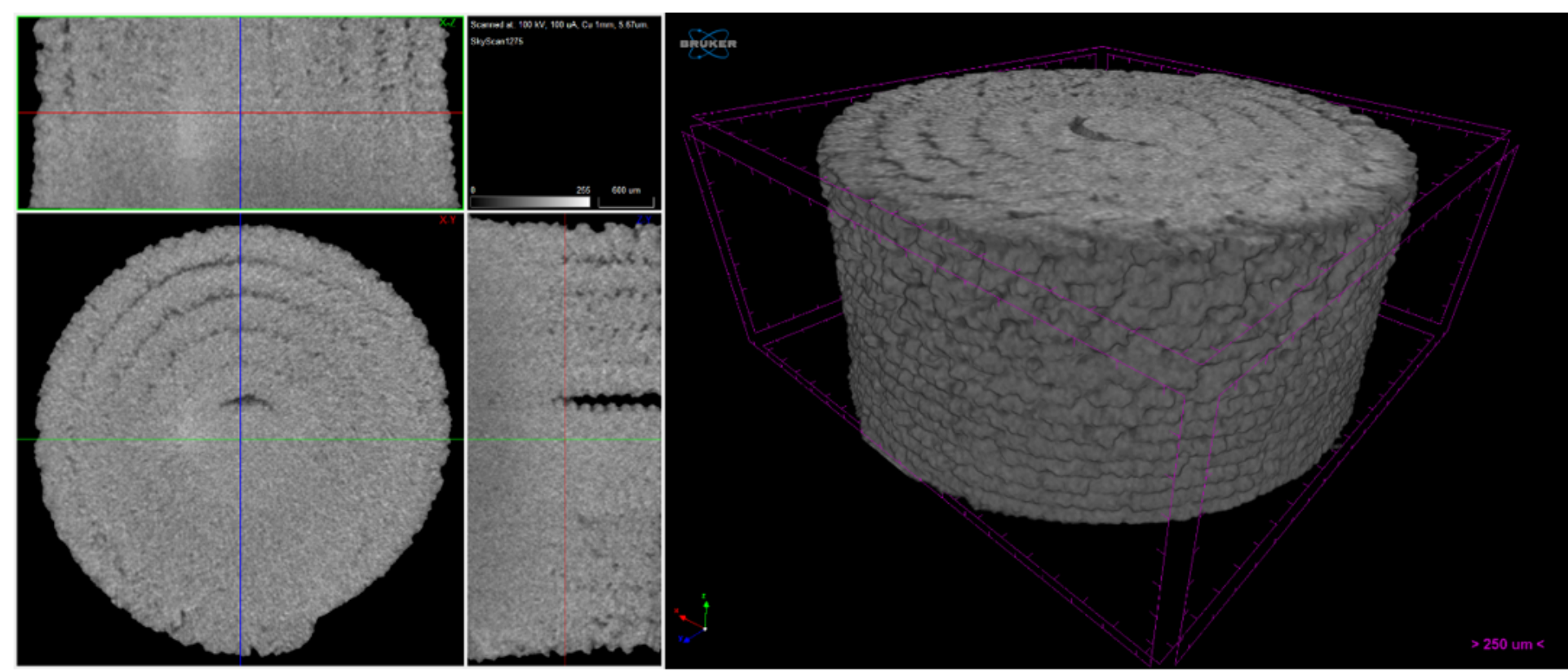

Figure 17

3D Object A
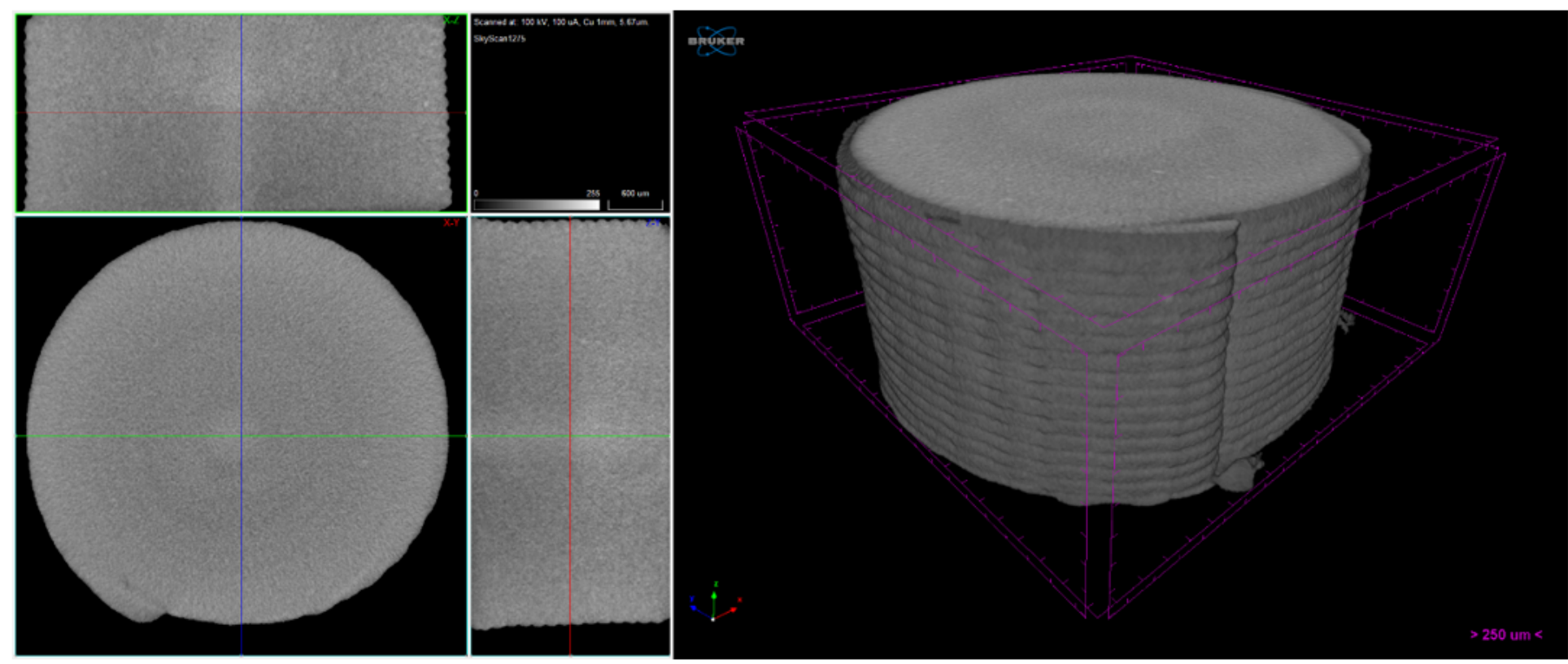

Figure 18

3D Object B 


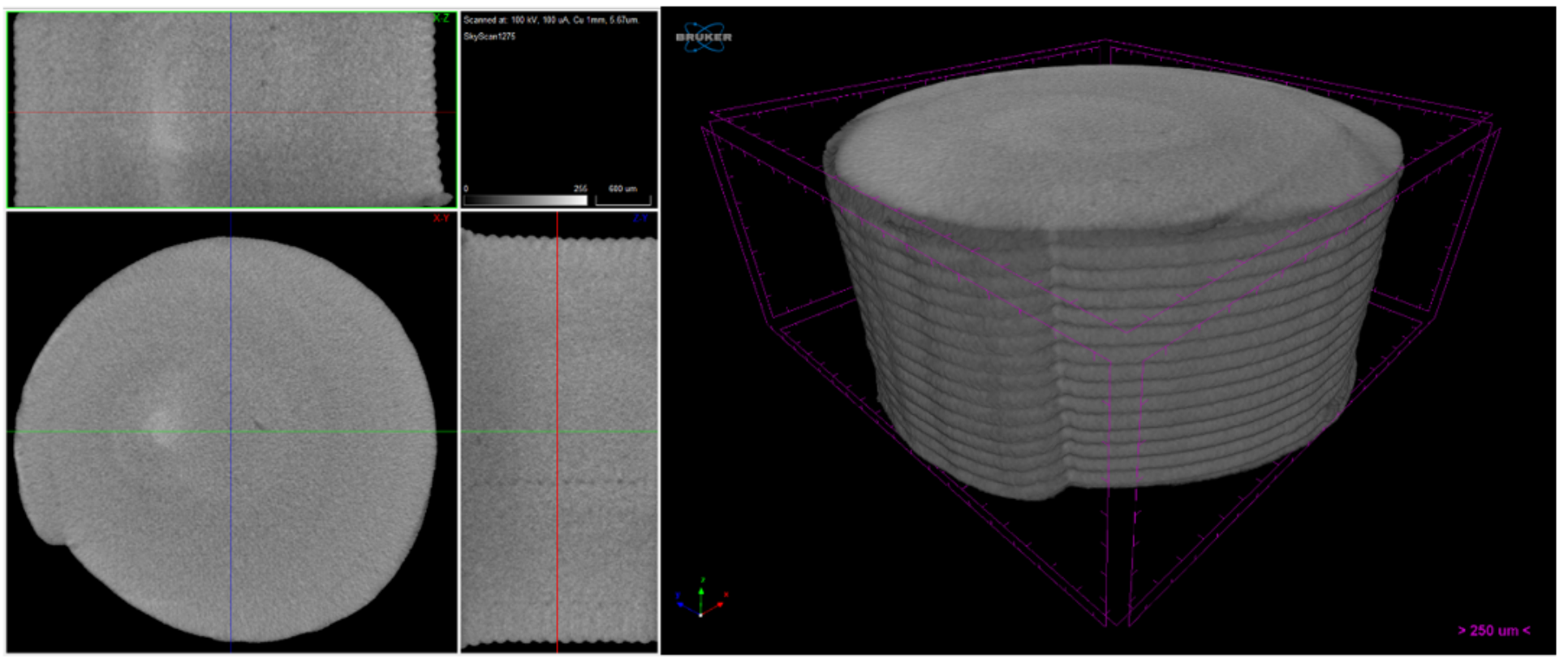

Figure 19

3D Object C

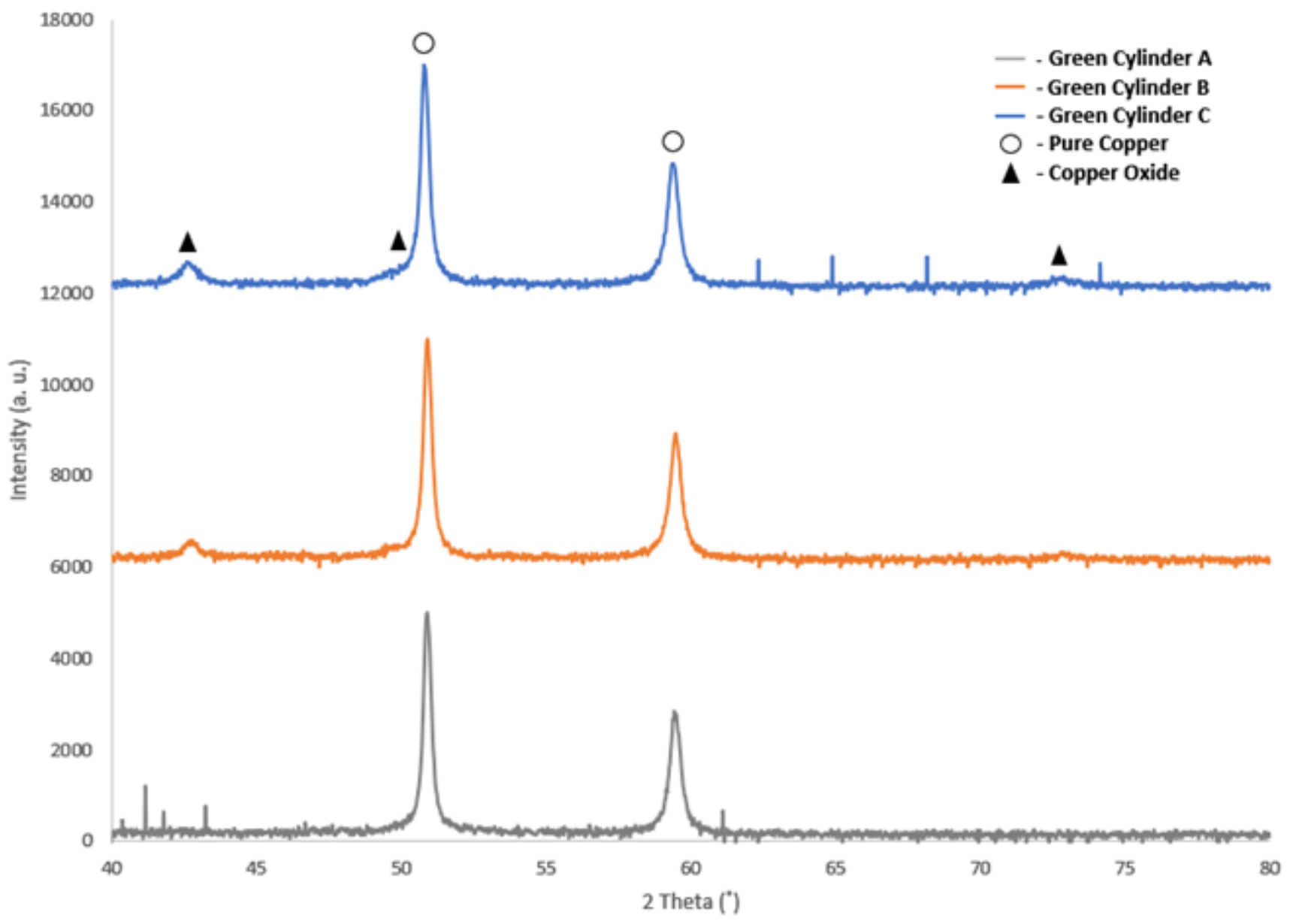

Figure 20 
XRD of the green 3D objects
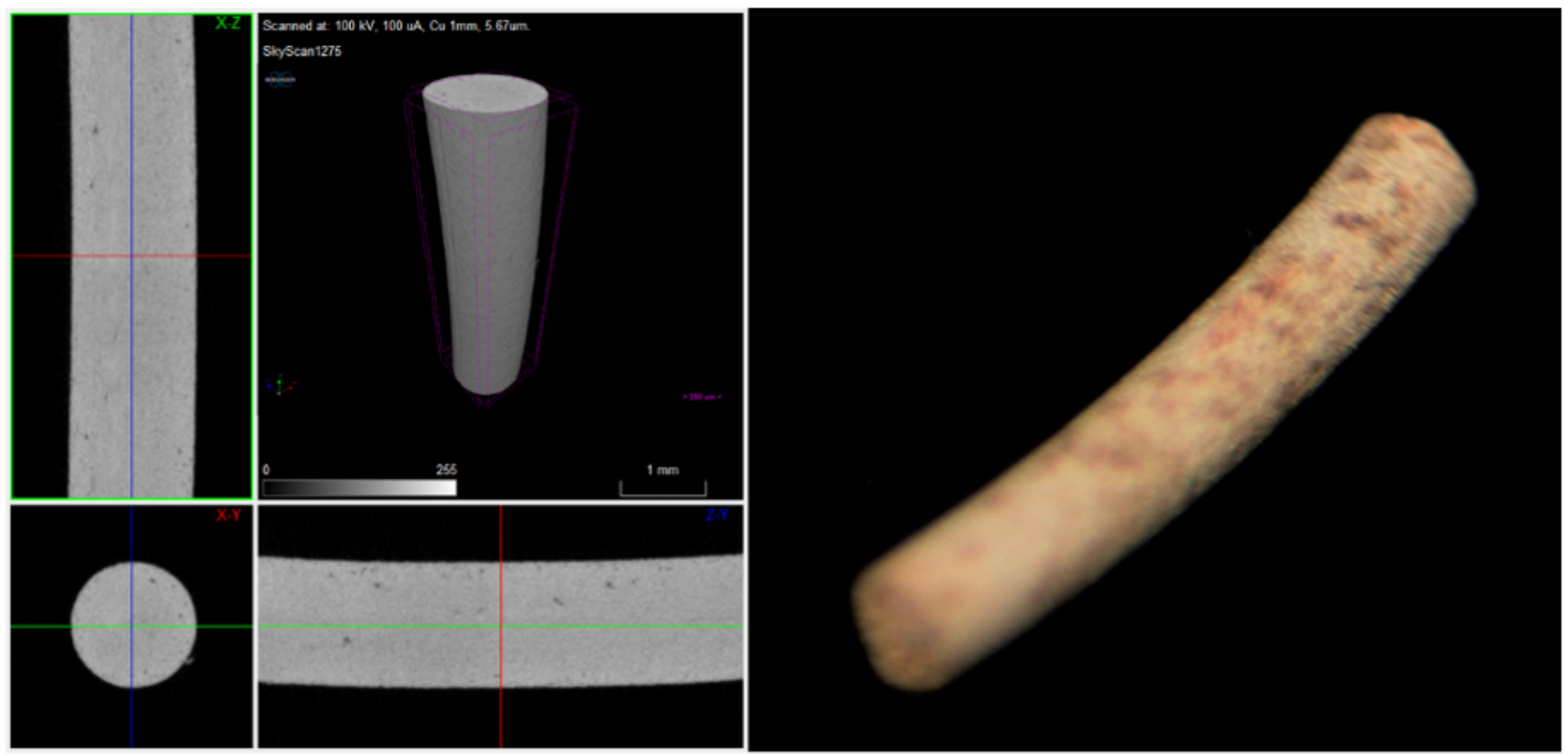

\section{Figure 21}

Filament A sintered (left) micro-CT; (right) macrography
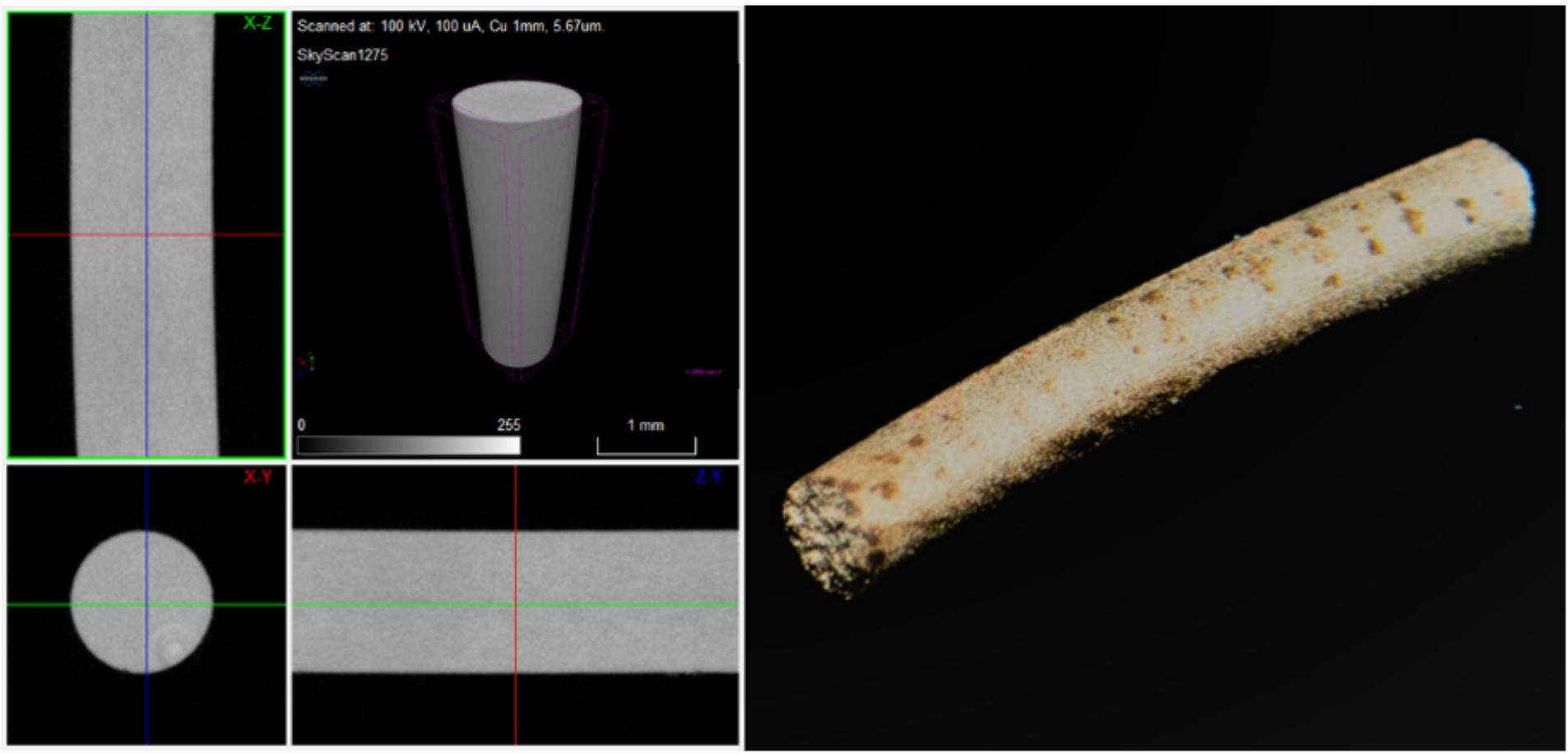

\section{Figure 22}

Filament B sintered (left) micro-CT; (right) macrography 

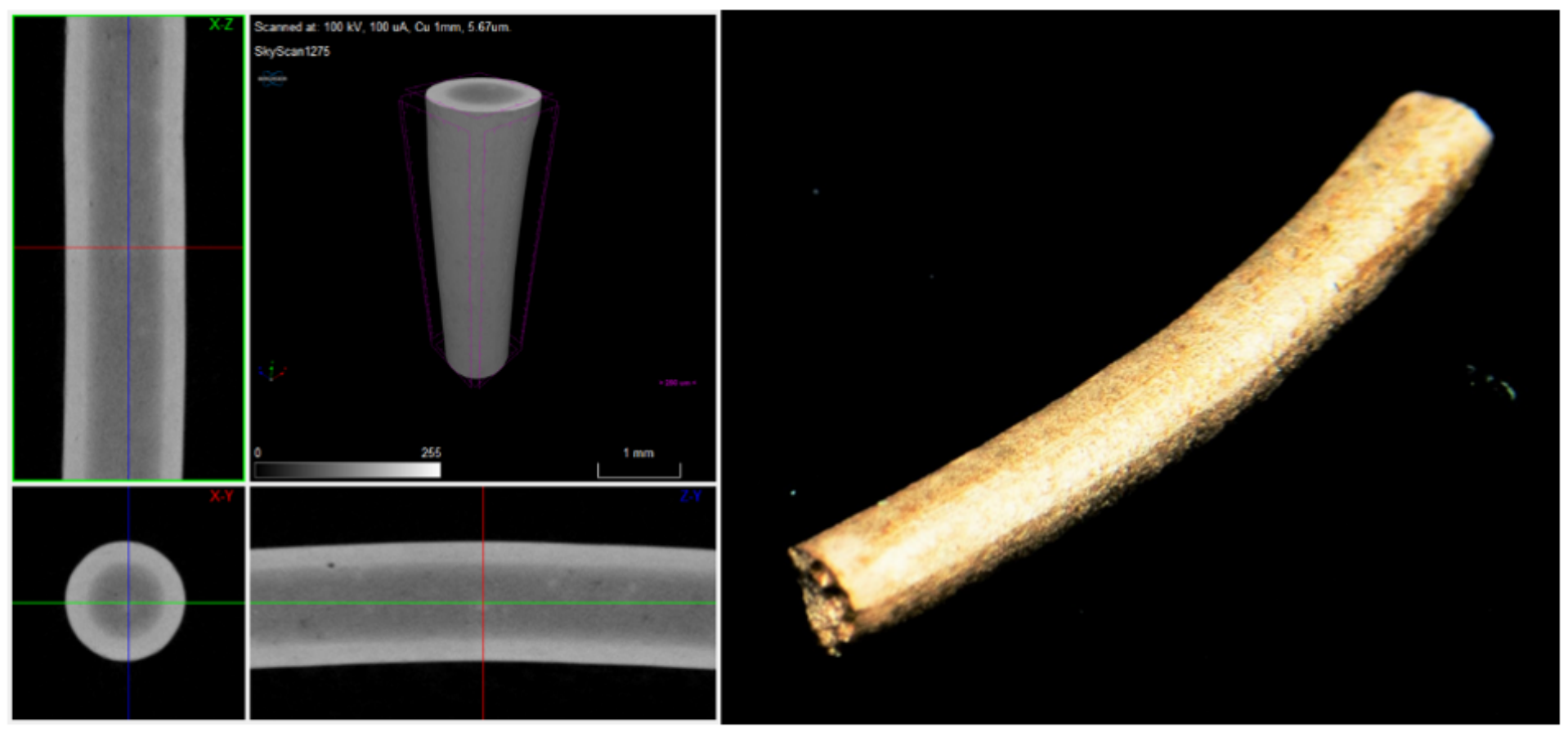

Figure 23

Filament C sintered (left) micro-CT; (right) macrography 
(a)
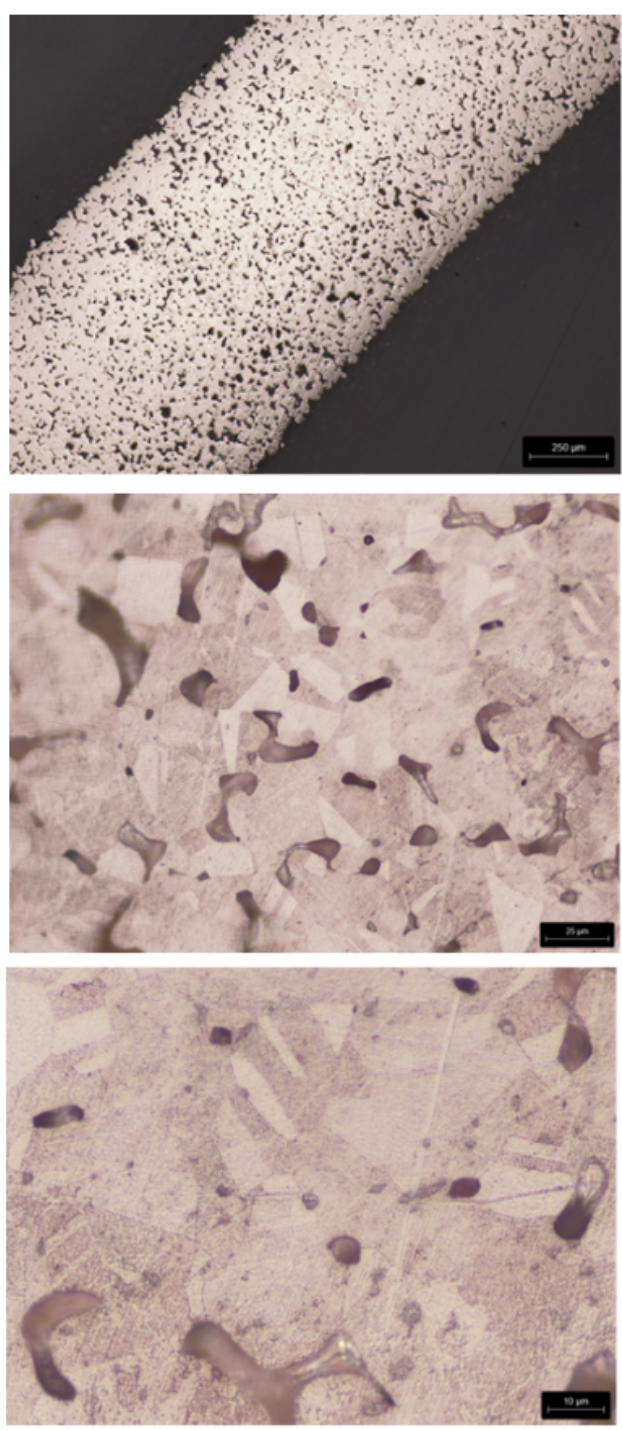

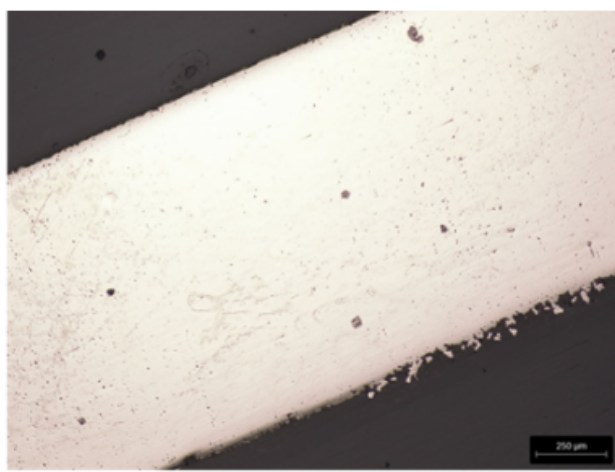

(b)
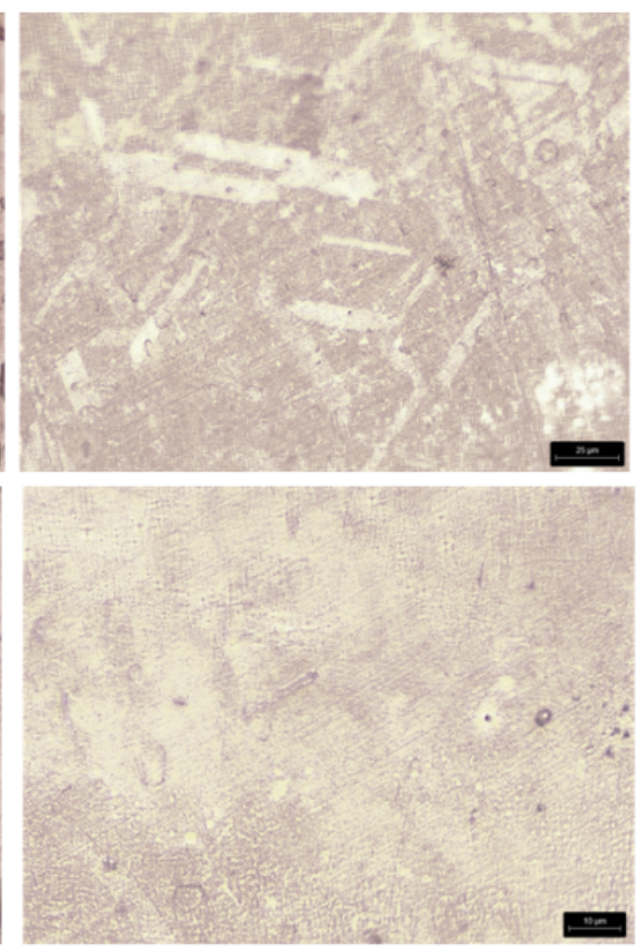

(c)
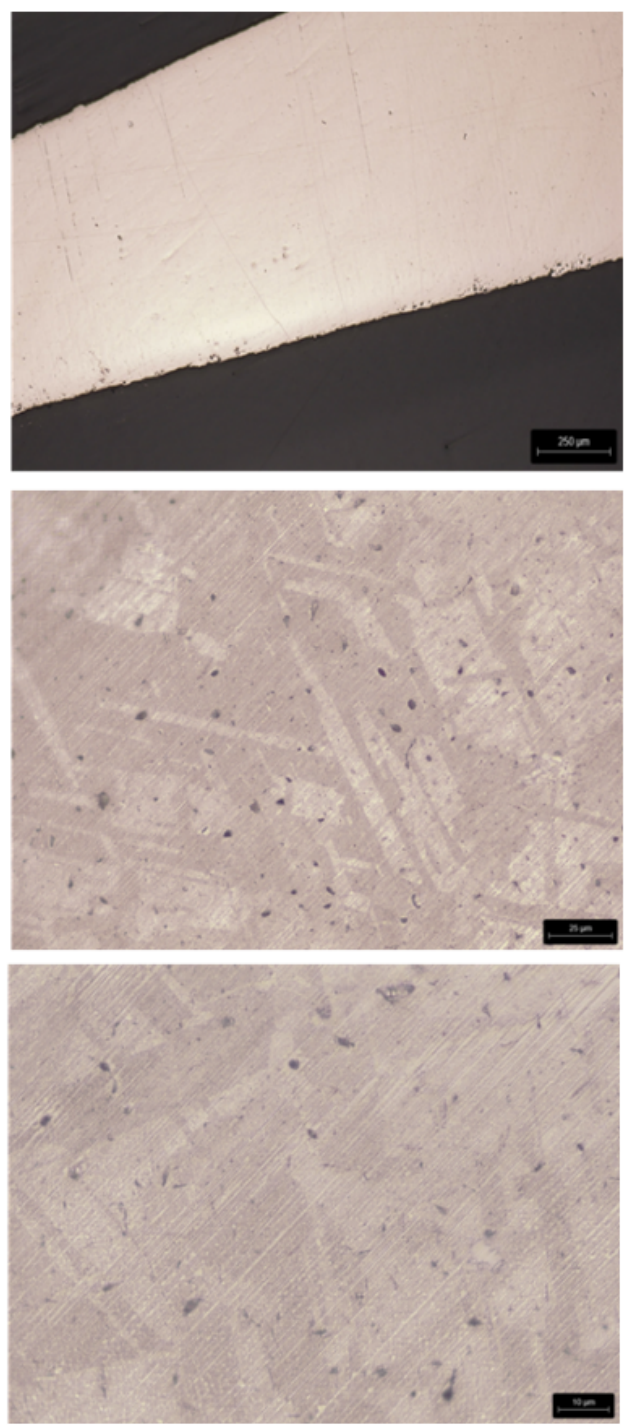

Figure 24

Microstructure of sintered parts after etching (OM); (a) from powder A; (b) from powder B; (c) from powder C 